Sharif University of Technology
Scientia Iranica
Transactions E: Industrial Engineering
http://scientiairanica.sharif.edu
IRAN ICA

\title{
Metaheuristics for a bi-objective green vendor managed inventory problem in a two-echelon supply chain network
}

\author{
M.M. Karampour ${ }^{\mathrm{a}}$, M. Hajiaghaei-Keshteli ${ }^{\mathrm{a}, \mathrm{b}}$, A.M. Fathollahi-Fard ${ }^{\mathrm{c}, *}$, \\ and G. Tian ${ }^{\mathrm{d}, \mathrm{e}, \mathrm{f}}$ \\ a. Department of Industrial Engineering, University of Science and Technology of Mazandaran, Behshahr, Iran. \\ b. Departamento de Ingeniería Industrial, Tecnologico de Monterrey, Puebla Campus, 72453, Mexico. \\ c. Department of Electrical Engineering, École de Technologie Supérieure, University of Québec, Montréal, Canada. \\ d. School of Mechanical Engineering, Shandong University, Jinan, 250061, China. \\ e. Key Laboratory of High Efficiency and Clean Mechanical Manufacture (Ministry of Education), Shandong University, Jinan \\ 250061, China. \\ f. National Demonstration Center for Experimental Mechanical Engineering Education, Shandong University, Jinan 250061, China.
}

Received 26 April 2019; received in revised form 23 April 2020; accepted 6 June 2020

\section{KEYWORDS}

Vendor managed inventory;

Green emissions;

Two-echelon supply

chain;

Multi-objective of red deer algorithm.

\begin{abstract}
Generally, finding an alternative solution for reducing fossil fuel consumption and greenhouse emissions of supply chain networks can shift Vendor Managed Inventory (VMI) to Green Vendor Managed Inventory (GVMI). Our literature search also confirms that the issue of environmental pollution and greenhouse emissions remains unfinished and requires further exploration. This motivates our attempt to offer the issue of green backorder for the VMI in a two-echelon supply chain network among the first studies. To this end, a bi-objective non-linear optimization model with the goal of maximizing the profit of inventory and minimizing the carbon emissions of transportation simultaneously is developed. Another contribution of this work is to propose three capable metaheuristics to optimally solve the problem in large-scale samples. In this respect, the Non-dominated Sorting Genetic Algorithm-II (NSGA-II) as a well-known method as well as Multi-Objective of Keshtel Algorithm (MOKA) and Multi-Objective of Red Deer Algorithm (MORDA) as two recent nature-inspired algorithms are applied first. The outputs confirm that the allowed shortage and failure to reduce costs point to the greater amount of shipping and orders based on sensitivities. With regard to the comparison made among algorithms, the MORDA significantly outperforms MOKA and NSGA-II.

(C) 2022 Sharif University of Technology. All rights reserved.
\end{abstract}

*. Corresponding author.

E-mail addresses: ie.karampour@gmail.com (M.M.

Karampour); mostafahaji@mazust.ac.ir (M.

Hajiaghaei-Keshteli):

amirmohammad.fathollahifard.1@ens.etsmtl.ca (A.M.

Fathollahi-Fard); tiangd2013@163.com (G. Tian)

doi: $10.24200 /$ sci.2020.53420.3228

\section{Introduction}

Academically, supply chain is defined as a transformation system of row materials, transportation of products, and purchasing at different levels from suppliers to customers [1-5]. Nowadays, the actual implementation of sustainability practices for the physical objects to the supply chain network throughout the world is unsustainable economically and environmentally [6-8]. Sustainable development and sustainability issues are 
active research topics in today's economic activities [9], requiring coordinated supply chain networks and enforcing decision-makers to focus on the environmental parameters based on the lines of sustainability [1012]. Based on this challenge, this study focuses on a two-echelon supply chain network between a supplier (vendor) and some retailers as buyers by contributing the environmental pollution to the problem in addition to the total cost $[10,13,14]$.

Vendor Managed Inventory (VMI) has been studied by several researchers with the aim of reducing the total cost, which can increase the performance of the supply chain [15]. Based on the concepts of VMI, the time and number of replenishments are determined by a vendor who has access to purchase input information and demand data [16]. In such systems, most of the inventory holding common costs are transferred from the vendors to retailers [17]. Upon shifting the inventory management to the VMI management, vendors can coordinate decisions on the inventory control and production [18]. If this VMI system is designed well, it can decrease both the inventory status and the system integrity by reducing the total cost [19].

The advantages of this VMI system have been realized and implemented by many retailers and suppliers [20]. The mentioned system shares the information pertaining to the points of sale and inventory with the other members of a supply chain network in order to reduce the bullwhip effect and improve the efficiency of the supply chain [21]. In addition, the VMI facilitates the cooperation between a supplier (vendor) and a retailer in the supply chain network to ensure responsiveness and efficiency [13-15]. In this regard, this VMI is an elastic replenishment system that enables a vendor to respond to real demands quickly. Therefore, it helps a vendor with the appropriate inventory levels of each product to adopt a proper approach to controlling these levels [22].

Another advantage of the VMI system is that by using this strategy, the retailers are exempt from all or part of the inventory costs. On the other hand, vendors can improve their production and transportation plans significantly with access to the demands made by the end customers of a supply chain network. Therefore, the inventory turnover and customer service level are improved at each stage of the supply chain [17]. Although the profits of vendors are variable, the VMI has always provided retailers with more profits. Taken together, this VMI reduces general costs of a supply chain network. However, the purchase under certain conditions between a retailer and a vendor is so significant $[14,15]$. In the long term, the vendor profit is more likely to increase compared to the profit to be gained in the short term [23].

Keeping in mind the aforementioned characteristics of the proposed VMI, this study contributes to the green backorder of this system called Green Vendor Managed Invertory (GVMI) and reduces the environmental pollution resulting from the transportation in a two-echelon supply chain network. In this regard, the main contributions of this study are outlined below:

- A new bi-objective GVMI model is developed;

- The model in small sizes is solved using the $\varepsilon$ constraint method and is compared with the results existing in the literature;

- Three multi-objective metaheuristic techniques namely Non-dominated Sorting Genetic AlgorithmII (NSGA-II), Multi-Objective of Keshtel Algorithm (MOKA), and Multi-Objective of Red Deer Algorithm (MORDA) are employed to solve large-scale samples;

- To improve the performance of the metaheuristics, a well-known calibration method so-called Response Surface Method (RSM) is employed;

- Three assessment metrics are considered for the quality of Pareto optimal solutions and computational time for metaheuristics;

- Based on a comparative study, MORDA exhibits a better performance in practice.

The rest of the research can be organized as follows. In Section 2, a relevant literature about the related papers formulating and solving the VMI concepts is collected. In Section 3, the GVMI model is formulated for a two-echelon supply chain network. Since this model is NP-hard [17,24], the $\varepsilon$-constraint method and three old and recent metaheuristics for multi-objective programming are presented in Section 4. In Section 5 , the $\varepsilon$-constraint method is used to solve the model for one vendor and several retailers as small sizes with some analyses on different shortage values. Then, in Section 6, the problem in large-scale samples is optimized by three metaheuristic algorithms. In this regard, the adjusted parameters of the used algorithms is selected by RSM and three assessment metrics are utilized to compare the methods. Finally, the conclusion and suggestions are presented in Section 7 .

\section{Literature review}

Inventory management concepts have been mathematically modeled and solved by various papers. The use of the mathematical models called operations research in the VMI was first introduced by Dong and Xu [23] in 2002. They presented a mathematical model to compare the traditional system with the VMI considering constant demands, no shortage, and certain delivery times in their work. They conducted investigations in both short and long terms and found that the inventory costs of retailers and vendors were lower 
upon implementing the new system than those in the traditional system. In 2007, Yao et al. [20] used the same assumptions proposed by Dong and $\mathrm{Xu}$ [23]. They also assumed that the number of orders made by a vendor was the same as the number of orders made by a retailer. Then, they compared the traditional supply chain system with the VMI system. In another research, Nachiappan and Jawahar [25] used Genetic Algorithm (GA) to solve VMI model under infinite or unauthorized backorder cost conditions by considering only one vendor with three retailers. Later, Sadeghi et al. [26] introduced a mathematical model for the VMI considering one vendor and several retailers for two purposes. In their model, the rate of retailer demands was certain with some constraints including total budget, vendor total replenishment frequency, required space, and inventory mean. Therefore, they attempted to determine the size of order and replenishment sequence. They managed to ascertain the optimal trip from retailers to vendors and the optimal number of machines used for production in order to minimize costs and maximize reliability. Since this was an NPhard problem, NSGA-II was the algorithm employed to solve the model. Then, it was compared with multiobjective Simulated Annealing (SA) algorithm. In 2010, Wang et al. [10] commented on the work of Yao et al. [20] and demonstrate the conflict in the buyer's order in their conclusion.

Furthermore, Nia et al. [27] introduced a multicommodity VMI model in their paper. They used the optimal Economic Order Quantity (EOQ) model and added the cost of carbon tax to the green approach. Then, they considered the warehouse capacity, delivery constraints, order boundaries, and constraints on a number of pallets by signing this VMI contract between vendors and retailers. Finally, a hybrid of GA and Imperialist Competitive Algorithm (ICA) was presented to solve the model. Their model was validated by comparing the proposed algorithm with general ideas. In addition, a low boundary was obtained for the model by freeing constraints continuously. Similarly, Park et al. [28] used machine learning and GA to simulate the appropriate values of variables in a VMI system and modeled vendors' profit using the Design Of Experiments (DOE) approach. In addition, Lee et al. [29] presented a model that shares inventory shortage cost between suppliers and customers with VMI and EOQ model considering the justifiability of shortage and shortage cost imposed on vendors facing limited warehouse storage. In their paper, the abovementioned model was compared under four scenarios: a traditional system; an integrated system; a VMI model by sharing inventory shortage cost; and the last VMI model with constant movement cost and shared inventory shortage cost using an EOQ model with limited capacity. As shown in their work, this model decreases system-related costs by designing an appropriate contract. Then, it is compared with an integrated system. They also demonstrated that a VMI could bring about coordination between the supply chain network and constant movement cost and shared inventory shortage cost. In another research, Khan et al. [30] presented a VMI model with a single commodity during a two-stage supply chain network considering the incomplete quality of products. The commodity was owned by the vendor and was, yet, kept in the retailer's warehouses to be managed by the retailer. In this policy, the retailer's investment is not entangled with the inventory. Therefore, the retailer is guaranteed to be available like a constant customer and the vendor is always available, too. Moreover, the movement time and the quantity of inventory are ensured between vendors and retailers.

Development of VMI models for the supply chain network design problem remains an active subject matter in the last decade $[2,5,6,12]$. In this respect, Pasandideh et al. [31] presented a VMI model for a two-echelon supply chain network between a vendor and a retailer with a multi-product supposition. The aim of their model was to determine the quantity of orders and maximal inventory level of backlogs to minimize inventory costs. In their study, the warehouse capacity was supplied and the number of orders placed by retailers was limited. They used GA to address their model. Later in 2014, Diabat [24] introduced a VMI model for the two-echelon supply chain of a vendor and some retailers such that the product price was considered linearly and decreasingly dependent on demands. In the model proposed by the above author, profit was regarded as the income of sales minus the costs of production and distribution (depending on the product stream and the costs of product transfer) and the costs of ordering and replenishment. Moreover, there are minimal and maximal transfers in his model in which vendors have limited capacities. Using a hybrid of GA and SA, he solved the proposed model to achieve the best solutions and compared it with the main algorithms. In another VMI solving using metaheuristics, Nia et al. [32] considered a VMI model with one retailer, one vendor, and several products in a fuzzy environment. In their model, shortage was allowed and there were some constraints on the warehouse capacity, delivery, orders, and number of pallets. Also, the warehouse capacity and quantity of orders were considered in the form of fuzzy logic. They used an Ant Colony Optimization (ACO) to solve their model. They also provided a comparative study between ACO and different versions of evolutionary algorithms based on GAs. In another research, Hariga et al. [33] studied a VMI model with the supposition of a storage contract such that it was allowed to send retailers' products nonconsecutively and to consider the storage constraints. 
Their developed model also calculates extra costs of storage for the retailers. They proposed an exact solution solver by GAMS software. They introduced an efficient method to obtain a near-optimal solution for delivery scheduling. The results indicated that considerable savings were made in the presence of VMI when products were sent to retailers consecutively and equally. Then, Taleizadeh et al. [34] presented a bi-level programming model for the VMI including one vendor and some retailers in a noncompetitive environment with the perishability rate of raw materials and final products. In this market, demands for final products are considered fixed. The aim of the retailer model is to optimize the replenishment sequence of raw materials, replenishment cycle of products, and production rate such that the total profit of supply chain network can be maximized. In their model, they used the game theory with the Stackelberg game. They regarded a vendor as the leader, whereas retailers were regarded as followers in this case.

Later in 2017, Kaasgari et al. [17] developed a VMI model for perishable products by considering a discount depending on the product lifetime. In order to address their model, they utilized two well-known methods, namely GA and Particle Swarm Optimization (PSO). In 2018, Beklari et al. [35] proposed a VMI with the goal of maximizing inventory turnover in producer warehouse. Their main innovation was to employ a hybrid algorithm based on GA and PSO to solve their proposed problem.

Recently in 2019, Weraikat et al. [11] developed a VMI system to minimize the quantity of expired products. The application of the model was tested in a pharmaceutical supply chain using a real case study. They solved the model using Monte-Carlo simulation algorithm. They confirmed the role of safety stock to improve the performance of the pharmaceutical supply chain. Safaeian et al. [36] also considered a multiobjective optimization model for a two-echelon supply chain network with several suppliers and retailers. They applied the NSGA-II to determine an interaction of four goals with each other including the total cost, quality and price of products, and satisfaction levels. More recently, Dai et al. [37] proposed a VMI for perishable products by considering the stock and price, which is dependent on demand. They solved it via the exact method and set sensitivity to the price and stock in different cases.

Following a quick review of the aforementioned works, they can be divided into three classifications. Most of them have focused on developing novel optimization models. A group of recent works mainly tries to offer new algorithms to better solve the VMI problem. Finally, a few studies have worked on improving both research classifications. By proposing a GVMI for a two-echelon supply chain network and solving it by three metaheuristics, this study provides new contributions in the literature.

Generally, there are several methods and elements for formulating a VMI problem. These factors not only make the VMI more practical but also increase its complexity and computational cost. These facts confirm that an efficient algorithm is required when the problem is more complex than its general version to determine an optimal solution. Based on the theory of No Free Lunch (NFL) [38], no metaheuristic is able to solve all optimization problems with the highest performance. Therefore, a new method may outperform existing algorithms for a particular problem like the proposed GVMI $[2,4,5,9,10]$. To alleviate these limitations, this study applies two recent metaheuristics, i.e., MOKA and MORDA, for the first time in the literature.

In conclusion, this study uses not only NSGAII to solve the model but also MOKA and MORDA as two recent algorithms in terms of multi-objective programming. To the best of our knowledge and based on the aforementioned findings in the literature, the related studies have paid less attention to the environment effects and greenhouse emissions in the logistics of the VMI problem. In this regard, this study offers the concept of GVMI as the main contribution of this paper. In addition, this research is derived from the papers by Diabat [24] and Nia et al. [27] such that storage limits and quantity of orders are considered in conjunction with shortage costs.

\section{Problem description and model formulation}

This study establishes a GVMI model for a two-echelon supply chain network. It investigates greenhouse emissions or environment effects to reduce the amount of pollution by considering the customers facing shortage of storage and number of orders. In the developed model, the first objective aims to maximize the benefits of selling the products at a cost of manufacturing, distribution, and inventory in the case of no penalties. The second objective is to minimize the greenhouse emission from product transport. Notably, the main innovation of the proposed model is that it considers a new objective function to control greenhouse emissions as the second objective function. Figure 1 gives a graphical depiction of the GVMI model. In this figure, there is only one vendor with some retailers in which the shipping from the vendor to retailers is identified. The costs comply with the vendor's demand.

In the case of the developed model, the assumptions derived from the related papers [24,27] are summarized as follows:

- Expenditures arise upon facing product shortage following penalties for the vendor;

- A limitation is set for stock by retailers; 


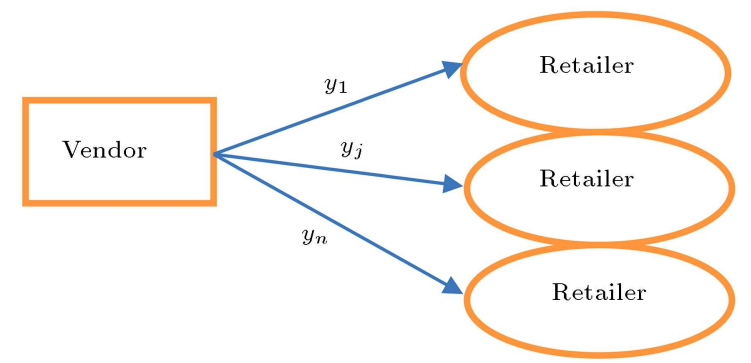

Figure 1. GVMI model with one vendor and some retailers.

- The number of orders for the vendor is predefined;

- The volume of products sent from the vendor to retailers is limited to maximum and minimum amounts;

- The relationship between the prices set by both the vendor and retailer is linear.

The notations of the developed model are introduced as follows:

\section{Indices:}

$j \quad$ Index of retailers $(j=1, \ldots, n)$

\section{Parameters:}

$a_{j} \quad$ The initial price of a product based on the demand of retailer $j$

$k_{j} \quad$ Reduction slope of price based on the demand of retailer $j$

$y_{j \min } \quad$ A lower bound for the number of products shipped to retailer $j$

$y_{j \max } \quad$ A upper bound for the number of products shipped to retailer $j$

$\delta \quad$ Manufacturing cost per unit

$\theta_{j} \quad$ The cost of flow of products from the vendor to retailer $j$

$v_{j} \quad$ Indirect cost of shipping products to retailer $j$

$\beta_{j} \quad$ Amount of greenhouse emission from each unit of shipment to retailer $j$

$H_{b j} \quad$ Maintenance service for retailer $j$

$\pi_{b j} \quad$ The cost of shortages for retailer $j$

$S_{b j} \quad$ The cost of ordering for retailer $j$

$S_{s} \quad$ The cost of ordering for vendor

$H_{s} \quad$ Maintenance service for vendor

$T I C_{j} \quad$ The total cost of maintenance service from vendor to retailer $j$

C The capacity of vendor for manufacturing and shipment of products

$f \quad$ Space for per unit of products

$F_{j} \quad$ Space capacity of retailer $j$
$C C \quad$ Transport capacity for products between vendor and retailers

$N \quad$ The maximum number of orders received from retailers

\section{Variables:}

$y_{j} \quad$ The volume of submitted products from vendor to retailer $j$

$Q_{j} \quad$ Amount of ordering from retailer $j$

$b \quad$ Amount of shortage from vendor

$Z_{1}\left(y_{j}\right) \quad$ The first objective function to maximize the profit of the system

$Z_{2}\left(y_{j}\right) \quad$ The second objective function to minimize the greenhouse emission of the system

In this research, a vendor with some retailers exists in which the vendor has a convention with each retailer $\left(y_{j}\right)$ according to the volume of the received products. In addition, retailers have a specified value for selling products. The following formulas are given according to the related articles [24,27] in which the relationship between the price of vendor and demand of retailer is linear and reduction to linear form:

$$
\begin{gathered}
P\left(y_{j}\right)=a_{j}-k_{j} y_{j} \quad \forall j, \\
y_{j \min } \leq y_{j} \leq y_{j \max } \quad \forall j .
\end{gathered}
$$

As can be seen, the products have the initial price $a_{j}$ and slope of $k_{j}$ according to the quantity of received products. The function is $P\left(y_{j}\right)$, as shown in Eq. (1). Accordingly, the mathematical formula for the developed GVMI problem is given as follows:

$$
\begin{aligned}
\operatorname{Max} Z_{1}\left(y_{j}\right)= & \sum_{j=1}^{n}\left\{a_{j} y_{j}-k_{j} y_{j}^{2}-\delta y_{j}-v_{j} \theta_{j} y_{j}^{2}\right. \\
& \left.-T I C_{j}\right\}, \\
\operatorname{Min} Z_{2}\left(y_{j}\right)= & \sum_{j=1}^{n} \beta_{j}\left[\frac{y_{j}}{C C}\right],
\end{aligned}
$$

s.t.:

$$
\begin{aligned}
& T I C_{j}= \frac{\left(S_{s}+S_{b j}\right) y_{j}}{Q_{j}^{*}}+\frac{\left(H_{s}+H_{b j}\right) b^{* 2}}{2 Q_{j}^{*}} \\
&+\pi_{b j}\left(Q_{j}^{*}-b^{*}\right)^{2} / 2 Q_{j}^{*} \\
& Q_{j}^{*}=\left(\frac{2\left(S_{s}+S_{b j}\right) y_{j}}{H_{s}+H_{b j}}\right)^{1 / 2} \times\left(\frac{H_{s}+H_{b j}+\pi_{b j}}{\pi_{b j}}\right)^{1 / 2} \\
& b^{*}=\frac{Q_{j}^{*} \pi_{b j}}{H_{s}+H_{b j}+\pi_{b j}}
\end{aligned}
$$




$$
\begin{aligned}
& \sum_{j=1}^{n} y_{j} \leq C, \\
& f y_{j} \leq F_{j}, \\
& \sum_{j=1}^{n} \frac{y_{j}}{Q_{j}^{*}} \leq N, \\
& y_{j \min } \leq y_{j} \leq y_{j \max }, \\
& y_{j} \geq 0 .
\end{aligned}
$$

In this study, two objective functions are considered for the developed GVMI model. Eq. (3) represents the maximum profit of the proposed network that includes selling products minus manufacturing cost, distribution cost and controlling the inventory in the case of fines on shortages. The second objective function in Eq. (4) aims to minimize the greenhouse emissions from the transportation system in terms of product shipment. The constraints of the developed model are scrutinized from Eqs. (5) to (12). Eq. (5) states the cost of inventory in the case of fines on shortages. Eq. (6) explores the number of economic ordering in terms of allowing shortages. In addition, Eq. (7) elaborates the optimal amount of shortages. Moreover, Eq. (8) shows the maximum capacity of vendor to retailers. In Eq. (9) determines the capacity of retailers to represent the maximum number of selling products. Eq. (10) shows the maximum number of orders received from retailers. In Eq. (11), the lower and upper bounds for the quantity of submitted products from vendor to retailers are determined. At the end, the continuous variables are guaranteed in Eq. (12).

According to the mentioned formulas, it should be noted that the manufacturing cost involves the manufacturing cost per unit product $\delta$ and submitted products $y_{j}$. In addition, the distribution cost equals the cost of products flowing from vendor to retailer $j\left(\theta_{j} y_{j}\right)$ multiplied by the cost of shipment products equal to $v_{j} y_{j}$. In this content, $v_{j}$ is the indirect cost of shipping products such as administrative costs set by 0.5 according to the related study [24]. In addition, TIC is the summation of maintenance and inventory costs related to the inventory control model and shortage cost. Finally, the number of optimized orders is computed by $Q_{j}^{*}$ and the amount of shortage is optimized to reduce the costs by $b^{*}$.

\section{Solution approach}

In this study, an exact approach called $\varepsilon$-constraint method is utilized to solve the small-sized problems and validate the developed GVMI model. In the case of using exact solution approach, the literature shows that when the size of the problem increases, the time consumption for the large-scale samples is significant. According to NFL, it is always possible that a new algorithm will reach a better solution to the current and new problems. Thus, this study presents three efficient approaches in metaheuristics. Given that the offered model is a multi-objective programming model, the structure of metaheuristics is changed [2]. In this case, at each iteration, the population of solutions is divided into some fronts. Each front consists of a set of solutions that do not dominate one another in this front. In this case, a solution dominates another solution if it has a better value for all objective functions [5]. The details of the encoding plan of metaheuristics are given below.

\subsection{Encoding plan}

To use a metaheuristic, plan representation is necessary to encode the model for the search phases in metaheuristic. The encoding plan also reveals how the constraints of the introduced mathematical model would be handled by metaheuristics. In this study, a two-stage technique, namely Random-Key (RK), is utilized, as illustrated in Figure 2. In the related articles, scholars have studied and employed this technique to encode the metaheuristics in a mathematical model $[2,5,39,40]$. The main reason for using this encoding strategy is to have a shorter computational time with no feasibility for repairing the solutions to encode the problem through a two-stage plan comprehensively [40-42]. The first stage is to generate a set of random numbers due to continuous search space of the metaheuristics. Next, this solution is converted into a feasible discrete solution using a procedure $[41,42]$. In our encoding plan, as shown in Figure 2, at first, a matrix with $|n|$ elements obtained through uniform distribution $\mathrm{U}(0,1)$ is formed. Then, according to each element of this array, the following formula is considered:

$$
y_{j}^{\prime}=y_{j} \times\left(y_{j \max }-y_{j \min }\right)+y_{j \min },
$$

where $y_{j \max }$ and $y_{j \text { min }}$ are defined as the upper and lower bounds of the number of products shipped to retailer $j$, respectively, as mentioned in Section 3. $y_{j}$ is the unfeasible array, vice versa, and $y_{j}^{\prime}$ is the feasible array to use in the objective functions. In this regard,

\begin{tabular}{|c|c|c|c|c|}
\hline$y_{1}$ & $y_{2}$ & $y_{3}$ & $y_{4}$ & $y_{5}$ \\
\hline 0.34 & 0.57 & 0.25 & 0.68 & 0.92 \\
\hline \multicolumn{5}{|c|}{$\downarrow$} \\
\hline 40.4 & 54.2 & 35 & 60.8 & 75.2 \\
\hline
\end{tabular}
metaheuristics search the feasible space through these two steps. In Figure $2, y_{j \max }$ and $y_{j \text { min }}$ are estimated at 20 and 80 , respectively, for this example.

\section{2. $N S G A-I I$}

The GA proposed by Holland [43] is a well-known

Figure 2. The proposed RK used. 


\begin{tabular}{|c|c|c|c|c|c|c|c|}
\hline \multirow{5}{*}{$\begin{array}{c}\text { Parent } 1 \\
\text { Parent } 2 \\
\text { Offspring } 1 \\
\text { Offspring } 2\end{array}$} & \multicolumn{7}{|c|}{ Single-point crossover: } \\
\hline & 0.52 & 0.18 & 0.82 & 0.73 & 0.35 & 0.89 & 0.57 \\
\hline & 0.93 & 0.65 & 0.75 & 0.61 & 0.59 & 0.36 & 0.29 \\
\hline & 0.52 & 0.18 & 0.82 & 0.73 & 0.59 & 0.36 & 0.29 \\
\hline & 0.93 & 0.65 & 0.75 & 0.61 & 0.35 & 0.89 & 0.57 \\
\hline \multirow{6}{*}{$\begin{array}{c}\text { Parent } 1 \\
\text { Parent } 2 \\
\text { Offspring } 1 \\
\text { Offspring } 2\end{array}$} & \multicolumn{7}{|c|}{ Double-point crossover: } \\
\hline & 0.52 & 0.18 & 0.82 & 0.73 & 0.35 & 0.89 & 0.57 \\
\hline & 0.93 & 0.65 & 0.75 & 0.61 & 0.59 & 0.36 & 0.29 \\
\hline & 0.52 & 0.18 & 0.75 & 0.61 & 0.59 & 0.89 & 0.57 \\
\hline & 0.93 & 0.65 & 0.82 & 0.73 & 0.35 & 0.36 & 0.29 \\
\hline & \multicolumn{7}{|c|}{ Uniform crossover: } \\
\hline \multirow{3}{*}{$\begin{array}{r}\text { Parent } 1 \\
\text { Parent } 2 \\
\text { Random mask }\end{array}$} & 0.52 & 0.18 & 0.82 & 0.73 & 0.35 & 0.89 & 0.57 \\
\hline & 0.93 & 0.65 & 0.75 & 0.61 & 0.59 & 0.36 & 0.29 \\
\hline & 1 & 0 & 0 & 1 & 0 & 1 & 0 \\
\hline \multirow{2}{*}{$\begin{array}{l}\text { Offspring } 1 \\
\text { Offspring } 2\end{array}$} & 0.52 & 0.65 & 0.75 & 0.73 & 0.59 & 0.89 & 0.29 \\
\hline & 0.93 & 0.18 & 0.82 & 0.61 & 0.35 & 0.36 & 0.57 \\
\hline
\end{tabular}

Figure 3. The crossover operators.

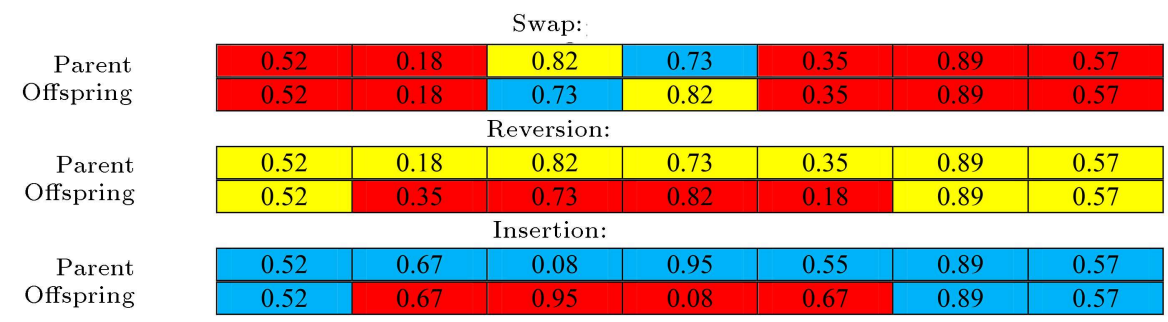

Figure 4. The mutation operators.

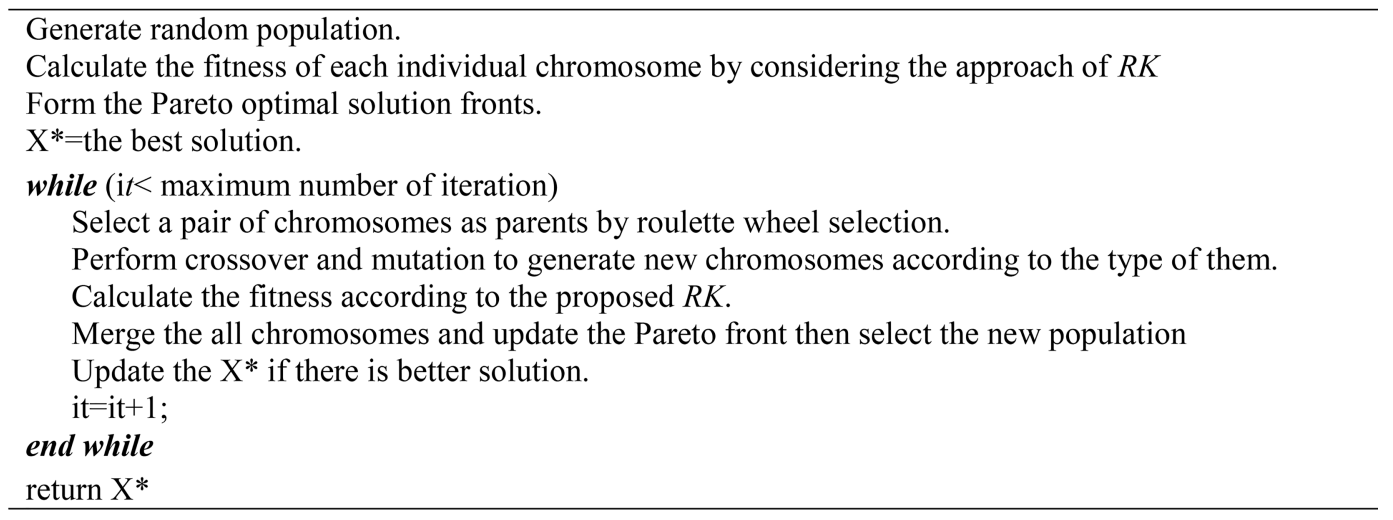

Figure 5. The pseudo code of NSGA-II.

metaheuristic that solves complex and non-linear optimization problems. The GA inspired by genetic science is a basic evolutionary algorithm that utilizes two various operators: crossover and mutation. Besides, exploration and exploitation are the two main search phases for any metaheuristics. Crossover maintains the exploration properties. In this term, three procedures are proposed, as illustrated in Figure 3. Generally, the crossover procedure selects two answers called parents. After that, they are combined with each other to generate two new solutions called offspring. In addition to this operator, the mutation searches the neighbors around good solutions to perform the exploitation phase. As such, three procedures are employed to perform the mutation operator in this study, as given in Figure 4. In the case of multi-objective optimization problems, Deb et al. [44] introduced the NSGA-II for the first time. Being a state-of-the-art metaheuristic, NSGA-II and its applications have been researched a lot and much related information can be found in many recent papers, e.g., $[1,2,10,12,17]$. The pseudo code of NSGA-II is addressed, as given in Figure 5.

\subsection{Multi-Objective of Keshtel Algorithm ( $M O K A)$}

Keshtel Algorithm (KA) offered by Hajiaghaei-Keshteli 
and Aminnayeri [45] is inspired by Keshtel's feeding. Keshtel is a bird in Anas family. The amazing behavior of this animal to search for food in the lake by swirling the closest neighbor around Keshtels is the basis of this nature-inspired algorithm. This metaheuristic divides the initial population into three groups: $N 1, N 2$, and N3. N1 includes the best solutions that find good food to swirl around the nearest neighbor. They are called lucky ones. The lucky Keshtels improve the exploitation properties and focus on the best solutions. N2 for each iteration moves around the lucky Keshtels. These Keshtels aim to do a local search around the best solutions. Finally, some of Keshtels fly and some new ones arrive on the lake. These Keshtels form the last group as $N 3$. In this case, some new solutions are generated randomly to maintain the exploration phase for the algorithm. To briefly show the procedures of the algorithm, assume that $N$ is a set of population members; then, we have:

$$
N=N_{1} \cup N_{2} \cup N_{3} \text {. }
$$

For each lucky Keshtel, the swirling process is done. For example, let the maximum number of swirlings $\left(S_{\max }\right)$ be equal to 3 . Maximum of $\left(2 \times S_{\max }-1\right)=5$ new solutions can be generated. The neighbor solutions can be generated by the following equations:

$$
\begin{aligned}
& \text { Position }_{1}=(a+(b-a)), \\
& \text { Position }_{2}=(a+(b-a) / 3), \\
& \text { Position }_{3}=\left(\text { Position }_{1}-(b-a) / 3\right), \\
& \text { Position }_{4}=(b-(b-a) / 3), \\
& \text { Position }_{5}=(b+(b-a) / 3) .
\end{aligned}
$$

For each member of $N 2$ set, the changes are made to its position toward virgin spots based on the positions of two lucky Keshtels. Let $Y_{i}$ be a member of $N 3$ set. Its position may change as follows:

$$
\begin{aligned}
& v_{i}=\lambda_{1} \times Y_{j}+\left(1-\lambda_{1}\right) \times Y_{t} \\
& Y_{i}=\lambda_{2} \times Y_{i}+\left(1-\lambda_{2}\right) \times v_{i},
\end{aligned}
$$

where $Y_{j}$ and $Y_{t}$ are two members selected randomly from $N 2$ set and different from $Y_{i} . \quad \lambda_{1}$ and $\lambda_{2}$ are random numbers selected from the uniform distribution at $[0,1]$.
In the case of the proposed multi-objective optimization model, a MOKA is required to be considered. In this MOKA, we only need to change the criterion selection for $\mathrm{N} 1$ and the selection of the next generation, which is similar to NSGA-II. In this term, the algorithm pseudo code is provided, as seen in Figure 6.

\subsection{Multi-Objective of Red Deer Algorithm (MORDA)}

Red Deer Algorithm (RDA) is another nature-inspired metaheuristic introduced by Fathollahi-Fard et al. $[46,47]$. The main contribution of this algorithm is to make a trade-off and balance between the phases in intelligent ways. The RDA inspired by Red Deer's mating uses the behavior of this animal in the breeding season to design search operators [48]. The initial population of RDA is divided into two groups: male Red Deer (RD) and hinds. Note that the algorithm generates the initial population of size $N_{\text {pop }}$. We select a set of the best RD for $N_{\text {male }}$ and the rest of them for $N_{\text {hind }}\left(N_{\text {hind }}=N_{\text {pop }}-N_{\text {male }}\right)$.

Next, each male roars to do a local search in the first step [49]. To update the position of males, Eq. (18), shown in Box I, is proposed, where $U B$ and $L B$ limit the search space. They are the upper and lower bounds of search space, respectively. Note that male $_{\text {old }}$ is the current position of male $\mathrm{RD}$, while male $_{\text {new }}$ is its updated position. Given that the roaring operator is random, $a_{1}, a_{2}$, and $a_{3}$ are generated randomly through uniform distribution at $[0,1]$.

Then, males are divided into commanders and stags. The number of stags is calculated as follows:

$$
N_{\text {stag }}=N_{\text {male }}-N_{\text {Com }}
$$

where $N_{\text {stag }}$ is the number of stags with regard to the population of males. Another main step of the algorithm is taken through the fighting procedure. The fighting between commanders and stags is considered in improving the exploitation properties of the algorithm. This fighting is controlled by the number of commanders and stags [50]. In this operator, two new solutions are generated using the following equations:

$$
\begin{aligned}
N e w 1 & =\frac{(\text { Com }+ \text { Stag })}{2}+b_{1} \times\left((U B-L B) \times b_{2}\right) \\
& +L B),
\end{aligned}
$$

$$
\text { male }_{\text {new }}=\left\{\begin{array}{ll}
\text { male } \left._{\text {old }}+a_{1} \times\left((U B-L B) \times a_{2}\right)+L B\right), & \text { if } a_{3} \geq 0.5 \\
\text { male } \left._{\text {old }}-a_{1} \times\left((U B-L B) \times a_{2}\right)+L B\right), & \text { if } a_{3}<0.5
\end{array}\right\}
$$




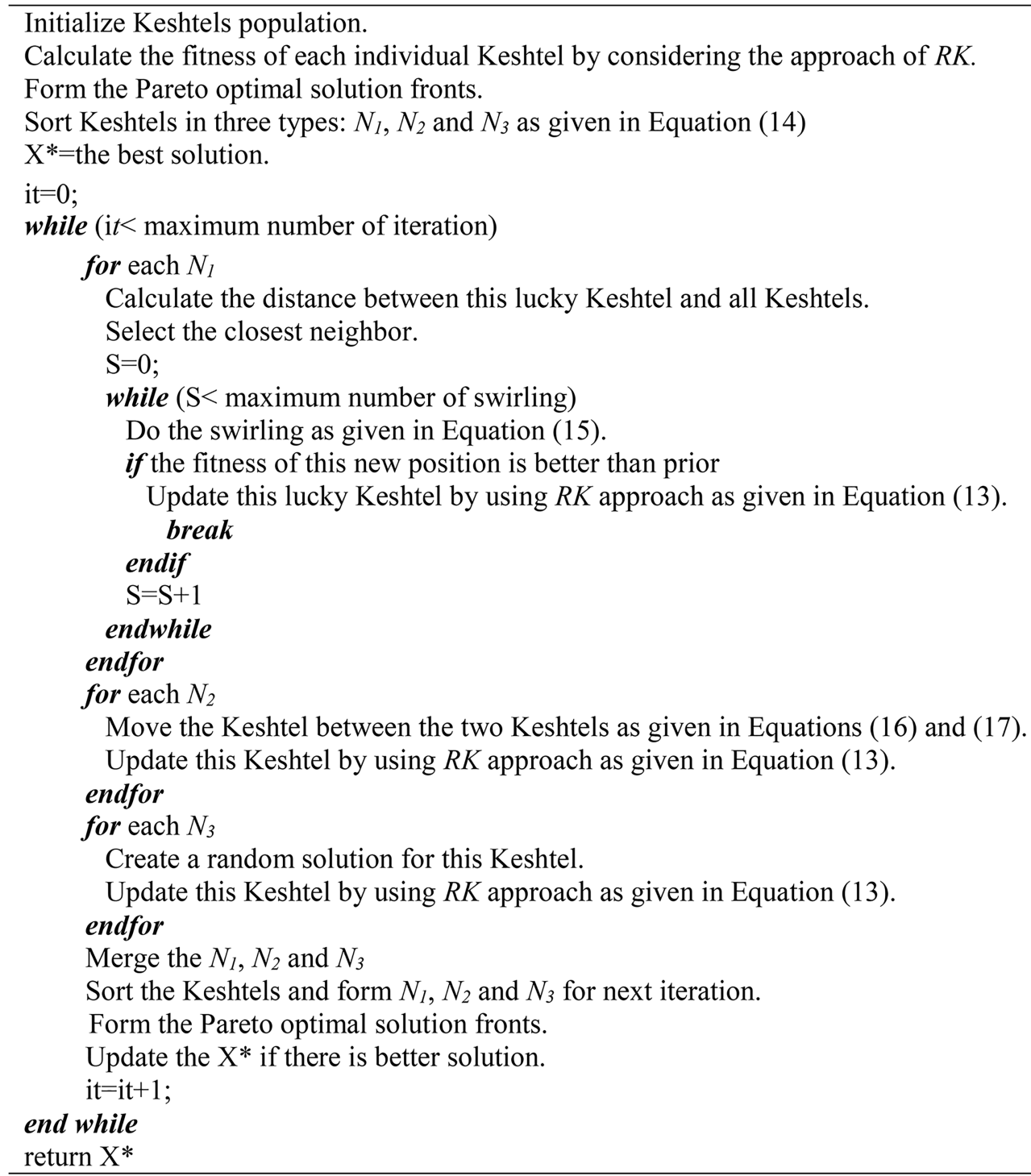

Figure 6. The pseudo code of MOKA.

$$
\begin{aligned}
\text { New2 } & =\frac{(\text { Com }+ \text { Stag })}{2}+b_{1} \times\left((U B-L B) \times b_{2}\right) \\
& +L B)
\end{aligned}
$$

where New1 and New2 are the two new solutions generated through the fighting process. Com and Stag are the symbols of commanders and stags, respectively. As the fighting is random, $b_{1}$ and $b_{2}$ are generated through uniform distribution function at $[0,1]$. The best solution among four ones is the new commander.

In the next step, the harems are formed by commanders. The number of hinds in each harem is directly related to the power of the commander. The mating behavior inside and outside of harems is formulated to maintain the exploration phase clearly. Moreover, stags mate with the nearest hind to perform the exploitation phase, again. This mating operator is done by the following formula:

$$
\text { offs }=\frac{(\text { Com }+ \text { Hind })}{2}+(U B-L B) \times c,
$$

where Com and Hind are the symbols of commanders and hinds, respectively. Offs is a new solution. Lastly, $c$ is generated randomly through uniform distribution at $[0,1]$.

Finally, based on the evolutionary concept, to select the next generation by roulette wheel, new RD are selected in this step [47-50]. Similar to two other metaheuristics employed, the MORDA is employed to solve the developed problem. The main difference is related to the selection of the better solution that should cover the multi-objective optimization and after each iteration, the non-dominated solution is updated. Having more details of MORDA, a pseudo code is given in Figure 7. 


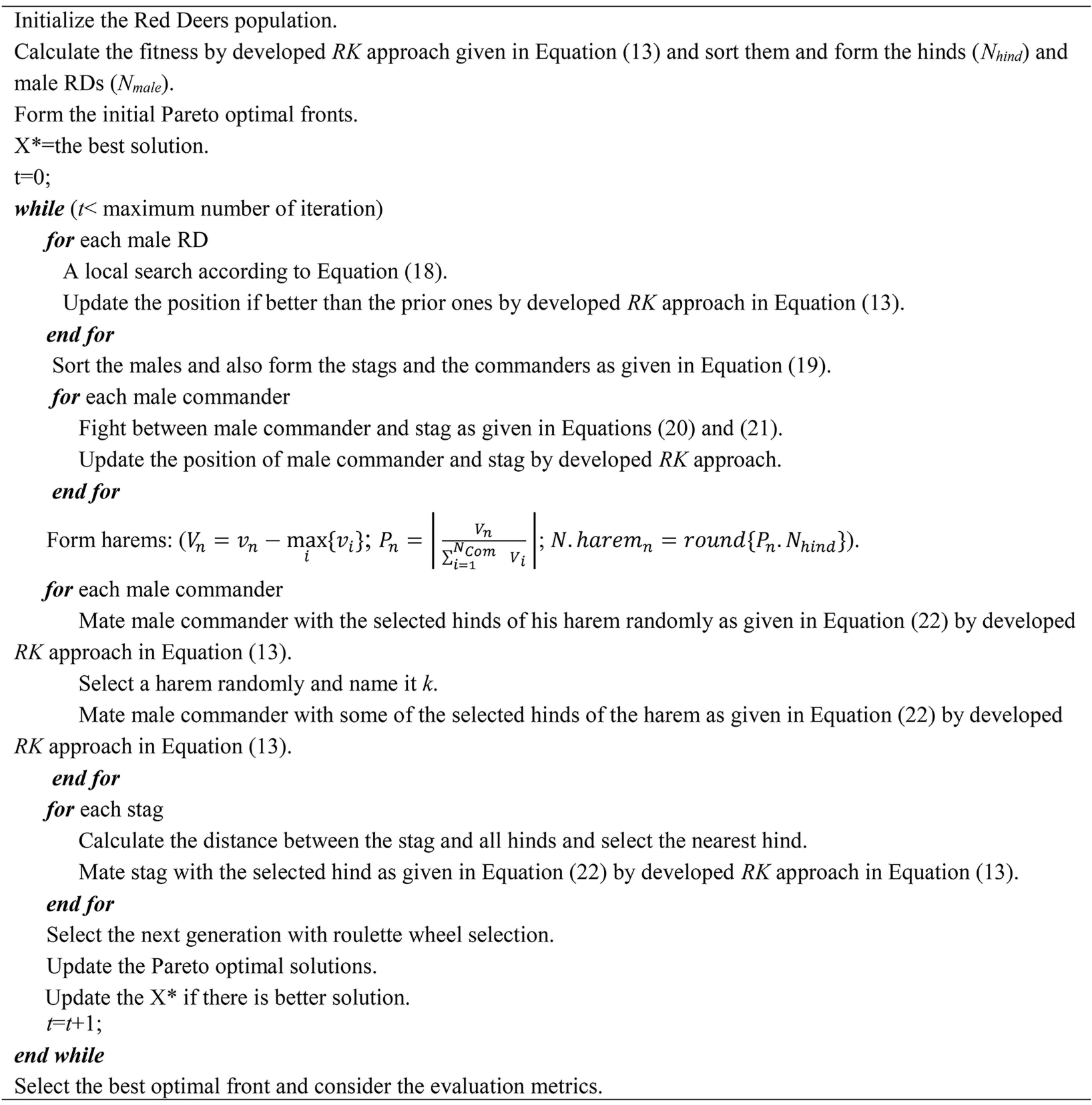

Figure 7. The pseudo code of MORDA.

\section{5. $\varepsilon$-constraint method}

To solve the small test problems, an exact approach is implemented. The $\varepsilon$-constraint method proposed first by Haimes et al. [51] is utilized by this research. Basically, this technique optimizes the problem based on one objective function as the main one. As such, the rest of objectives are limited by the allowable bounds as the constraints of the model. To generate more solutions, the bound is modified consecutively. Among the initial solutions and the solutions generated by modifying the bounds, non-dominated ones are selected, accordingly. Based on more details of this algorithm at hand, a brief formulation of the proposed problem is given as follows: $\max Z_{1}\left(y_{j}\right)$

s.t.:

Eqs. (5) - (12)

$Z_{2}\left(y_{j}\right) \leq \varepsilon_{j}$,

$Z_{j}^{\min }(x) \leq \varepsilon_{j} \leq Z_{j}^{\max }(x)$.

In this way, an exact solver using GAMS software is utilized to employ the $\varepsilon$-constraint method in this study. In the next part, to verify the viability of the developed GVMI model, small-sized problems are 
Table 1. Number of parameters for one retailer under infinite or unauthorized backorder conditions in P1-V1R1.

\begin{tabular}{cccccccccccc}
\hline $\boldsymbol{H}_{\boldsymbol{b} \boldsymbol{1}}$ & $\boldsymbol{S}_{\boldsymbol{b} \boldsymbol{1}}$ & $\boldsymbol{a}_{\boldsymbol{1}}$ & $\boldsymbol{k}_{\boldsymbol{1}}$ & $\boldsymbol{y}_{\mathbf{1} \min }$ & $\boldsymbol{y}_{\boldsymbol{1} \max }$ & $\boldsymbol{\theta}_{\boldsymbol{1}}$ & $\boldsymbol{\beta}_{\boldsymbol{1}}$ & $\boldsymbol{\pi}_{\boldsymbol{b} \boldsymbol{1}}$ & $\boldsymbol{F}_{\boldsymbol{1}}$ & $\boldsymbol{H}_{\boldsymbol{s}}$ & $\boldsymbol{S}_{\boldsymbol{s}}$ \\
\hline 9 & 300 & 80 & 0.01 & 1000 & 2000 & 0.005 & 0.1 & $\infty$ & 3000 & 9 & 150 \\
\hline
\end{tabular}

solved by this method and the results are compared with similar findings.

\section{Solving the small-sized problems with $\varepsilon$-constraint method}

Numeral examples have been defined in several stages. At the first stage, a single vendor is considered with one, three, and five retailers with/without backorder. Values of parameters in this example are taken from the study of [24] and are compared under infinite or unauthorized backorder cost conditions for this study with those in [23] and [25], as well. It should be noted that all test problems are solved using GAMS software by DICOPT solution (which is used for nonlinear models) in a computer with $1.7 \mathrm{~GB} \mathrm{CPU}$ and 6.0 GB RAM.

\subsection{One vendor with one retailer}

Tables 1 and 2 describe details of a problem with one vendor and one retailer under infinite or unauthorized backorder conditions (i.e., P1-V1R1).

Upon substituting the values given in Tables 1 and 2 into Eqs. (3) to (12) and solving the model, the optimum value is determined, as shown in Table 3 .

Table 2. Number of parameters for one vendor under infinite or unauthorized backorder conditions in P1-V1R1.

\begin{tabular}{ccccc}
\hline $\boldsymbol{C}$ & $\boldsymbol{\delta}$ & $\boldsymbol{C} \boldsymbol{C}$ & $\boldsymbol{f}$ & $\boldsymbol{N}$ \\
\hline 6150 & 40 & 100 & 0.2 & 50 \\
\hline
\end{tabular}

As shown in Table 3, the above model can be converted into the model described in the study done by Diabat [24] and the model validation is completely confirmed, although the model described in this study has two objectives and the second objective is the reduction of the greenhouse emission level. This is calculated in the last column. However, when the backorder cost is lower, after solving the model, the supply volume is logically reduced to avoid backorder, as given in Table 4.

As shown in Table 4, in the case of one vendor with a retailer, the model under the authorized backorder cost condition reducing the backorder cost increases both distribution and order quantities, reduces the optimum backorder value, and increases the profit compared to unauthorized backorder conditions. Also, given that the model has two objectives, by using the $\varepsilon$-constraint approach, the Pareto front can be worked out for the bi-objective model (i.e., P4-V1R1). To this end, lower and upper limits of the first objective $\left(Z_{1}\right)$ are divided into 10 equal points. The $\varepsilon$-constraint diagram is drawn in Figure 8 and the respective data are shown in Table 5 .

In Table 5, minimizing greenhouse emission function is taken into account first. In this case, the profit of the vendor is reduced (undesirable) and the greenhouse emission level is minimized (desirable). At end of the table, the vendor's profit increases (desired) and consequently, the emissions level is maximized (undesired). This is indicative of the conflict between

Table 3. The comparison of P1-V1R1 in our study and those in other similar researches.

\begin{tabular}{cccc}
\hline P1-V1R1 & $\boldsymbol{y}_{\text {jopt }}$ & $\boldsymbol{Z}_{\mathbf{1}}^{*}$ & $\boldsymbol{Z}_{\mathbf{2}}$ \\
\hline This study & 1535.03 & 26960.95 & 153.50 \\
Dong and Xu [23] & 1535 & 26960.49 & - \\
Diabat [24] using LINGO and hybrid algorithm & 1535 & 26960.49 & - \\
Nachiappan and Jawahar [25] using GA & 1535 & 26960.42 & - \\
\hline
\end{tabular}

Table 4. The GVMI model with one vendor and one retailer considering different shortages.

\begin{tabular}{ccccccc}
\hline Test problem & $\boldsymbol{\pi}_{\boldsymbol{b} \mathbf{1}}$ & $\boldsymbol{y}_{\boldsymbol{j} \text { opt }}$ & $\boldsymbol{Z}_{\boldsymbol{1}}^{*}$ & $\boldsymbol{Z}_{\mathbf{2}}$ & $\boldsymbol{Q}_{\boldsymbol{j}}^{*}$ & $\boldsymbol{b}^{*}$ \\
\hline P1-V1R1 & 1000000 & 1535.028 & 26960.550 & 153.50 & 277.043 & 277.038 \\
P2-V1R1 & 1000 & 1535.617 & 27004.793 & 153.62 & 279.576 & 274.633 \\
P3-V1R1 & 100 & 1540.290 & 27356.917 & 154.02 & 301.458 & 255.473 \\
P4-V1R1 & 10 & 1561.502 & 28975.745 & 156.15 & 467.558 & 166.985 \\
\hline
\end{tabular}




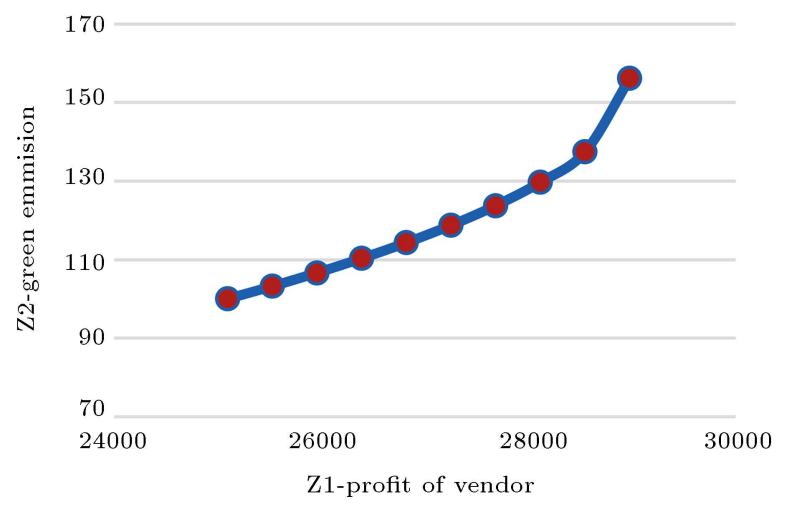

Figure 8. The Pareto optimal front of $\varepsilon$-constraint method for P4-V1R1.

Table 5. The results of $\varepsilon$-constraint method for P4-V1R1.

\begin{tabular}{cccc}
\hline P4-V1R1 & $\max \boldsymbol{Z}_{\mathbf{1}}$ & $\boldsymbol{\operatorname { m i n }} \boldsymbol{Z}_{\boldsymbol{2}}$ & $\boldsymbol{y}_{\text {jopt }}$ \\
\hline 1 & 25094.65 & 100.00 & 1000.000 \\
2 & 25525.88 & 103.22 & 1032.170 \\
3 & 25957.12 & 106.64 & 1066.413 \\
4 & 26388.35 & 110.32 & 1103.191 \\
5 & 26819.58 & 114.32 & 1143.173 \\
6 & 27250.81 & 118.74 & 1187.385 \\
7 & 27682.05 & 123.76 & 1237.551 \\
8 & 28113.28 & 129.70 & 1297.038 \\
9 & 28544.51 & 137.45 & 1374.533 \\
10 & 28975.75 & 156.15 & 1561.376 \\
\hline
\end{tabular}

Table 6. The parameters for retailers in P1-V1R3 under infinite or unauthorized backorder conditions.

\begin{tabular}{cccc}
\hline $\boldsymbol{j}$ & $\mathbf{1}$ & $\mathbf{2}$ & $\mathbf{3}$ \\
\hline$H_{b j}$ & 7 & 8 & 9 \\
$S_{b j}$ & 10 & 20 & 30 \\
$a_{j}$ & 20 & 19 & 18 \\
$k_{j}$ & 0.003 & 0.005 & 0.008 \\
$y_{j \min }$ & 2000 & 500 & 500 \\
$y_{j \max }$ & 4000 & 3000 & 1500 \\
$\theta_{j}$ & 0.003 & 0.005 & 0.008 \\
$\beta_{j}$ & 0.1 & 0.1 & 0.1 \\
$\pi_{b j}$ & $\infty$ & $\infty$ & $\infty$ \\
$F_{j}$ & 3000 & 3000 & 3000 \\
\hline
\end{tabular}

the objective functions. Figure 8 shows the $\varepsilon$-constraint diagram of P4-V1R1 model and draws the process of the objective functions, as observed.

\subsection{One vendor with three retailers}

Tables 6 and 7 show the parameters of the problem with one vendor and three retailers under infinite or unauthorized backorder cost conditions (P1-V1R3): the optimum solutions are worked out, as shown in Table 8 .

As given in Table 8, when the backorder cost is
Table 7. The parameters for the vendor in P1-V1R3 under infinite or unauthorized backorder conditions.

\begin{tabular}{ccccccc}
\hline $\boldsymbol{H}_{\boldsymbol{s}}$ & $\boldsymbol{S}_{\boldsymbol{s}}$ & $\boldsymbol{C}$ & $\boldsymbol{\delta}$ & $\boldsymbol{C} \boldsymbol{C}$ & $\boldsymbol{f}$ & $\boldsymbol{N}$ \\
\hline 9 & 150 & 6150 & 40 & 100 & 0.2 & 50 \\
\hline
\end{tabular}

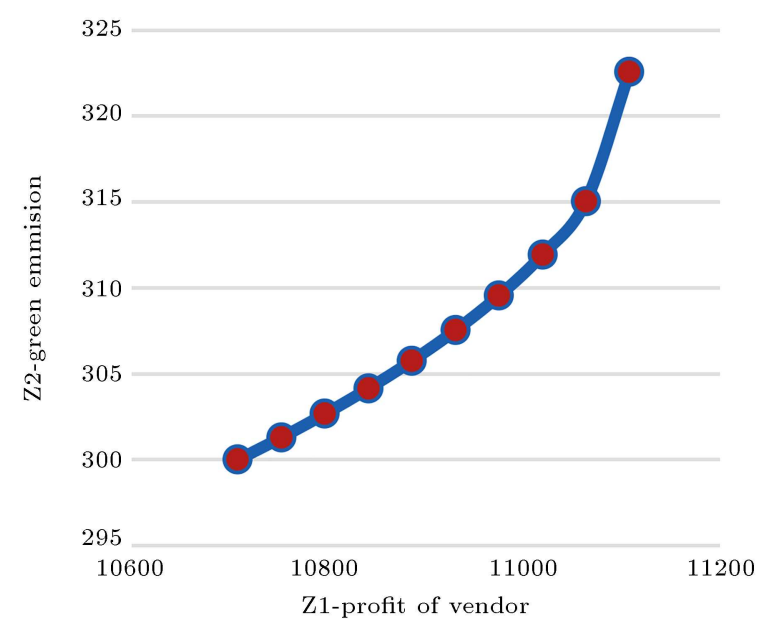

Figure 9. The Pareto optimal front of $\varepsilon$-constraint method for P4-V1R3.

extremely high, the developed GVMI model can be converted into other models and the model validation is confirmed completely, although this is a bi-objective model, value of which is shown in the last column. However, as shown in Table 9, the distribution quantity that avoids backorder is larger under conditions in which the backorder cost is lower and the model is solved.

As shown in Table 9, in the case of one vendor and three retailers, the model under authorized backorder cost conditions reducing the backorder costs increases distribution and order quantities and, therefore, decreases the optimum backorder value. Accordingly, the profit margin is greater than that in unauthorized backorder conditions. Also, given that this is a biobjective model, the application of the $\varepsilon$-constraint approach can determine the Pareto front for the biobjective model (i.e., P4-V1R3). To this end, the gap between higher and lower limits of the objective function (i.e., $Z_{1}$ ) is divided into 10 equal parts. The $\varepsilon$-constraint diagram is shown in Figure 9 and the respective data are shown in Table 10.

According to Table 10, minimization of the greenhouse emission function as the second objective was taken into consideration first. In this case, the vendor's profit is reduced (undesired) and the emission level is minimized (desired), while at the end of the table, the vendor's profit is increased (desired) and consequently, the emission level is maximized (undesired); moreover, this is indicative of the conflict between the objective functions. In addition, Figure 9 shows the Pareto optimal front for the sample P4-V1R3 in the GVMI model and the process of the objective functions. 
Table 8. The comparison of P1-V1R3 from our study with other same researches.

\begin{tabular}{cccccc}
\hline P1-V1R3 & $\boldsymbol{y}_{\mathbf{1} \boldsymbol{p} \boldsymbol{t}}$ & $\boldsymbol{y}_{\mathbf{2 o p t} \boldsymbol{t}}$ & $\boldsymbol{y}_{\mathbf{3 o p t}}$ & $\boldsymbol{Z}_{\mathbf{1}}^{*}$ & $\boldsymbol{Z}_{\mathbf{2}}$ \\
\hline This study & 2000 & 709.54 & 500 & 9903.13 & 320.95 \\
Diabat [24] using LINGO & 2000 & 710 & 500 & 9903.11 & - \\
Nachiappan and Jawahar [25] using GA & 2002 & 673 & 500 & 9905.51 & - \\
Diabat [24] using a hybrid algorithm & 2001 & 675 & 500 & 9908.49 & - \\
\hline
\end{tabular}

Table 9. The GVMI model with one vendor and three retailers by considering different shortages.

\begin{tabular}{ccccccc}
\hline Test problem & $\boldsymbol{\pi}_{\boldsymbol{b j}}$ & $\boldsymbol{y}_{\boldsymbol{j} \text { opt }}$ & $\boldsymbol{Z}_{\mathbf{1}}^{*}$ & $\boldsymbol{Z}_{\mathbf{2}}$ & $\boldsymbol{Q}_{j}^{*}$ & $\boldsymbol{b}^{*}$ \\
\hline \multirow{2}{*}{ P1-V1R3 } & \multirow{2}{*}{1000000} & 709.533 & 9903.13 & 320.95 & 54.056 & 54.056 \\
& & 500 & & & 50.004 & 50.004 \\
& & & & & & \\
P2-V1R3 & \multirow{2}{*}{1000} & 709.879 & 9928.81 & 320.98 & 54.523 & 53.611 \\
& & 500 & & & 50.448 & 49.556 \\
& & & & & & \\
P3-V1R3 & \multirow{2}{*}{100} & 2000 & & & 85.147 & 73.403 \\
& & 512.667 & 10134.512 & 321.267 & 58.595 & 50.081 \\
& & 500 & & & 54.314 & 46.029 \\
& & & & & & \\
P4-V1R3 & \multirow{2}{*}{10} & 725.645 & 11107.410 & 322.565 & 89.819 & 33.266 \\
& & 500 & & & 83.666 & 29.881 \\
\hline
\end{tabular}

Table 10. The results of $\varepsilon$-constraints method for P4-V1R3.

\begin{tabular}{|c|c|c|c|c|c|}
\hline P4-V1R3 & $\max Z_{1}$ & $\min Z_{2}$ & $\boldsymbol{y}_{1 \circ p t}$ & $y_{2 o p t}$ & $y_{3 \circ p t}$ \\
\hline 1 & 10708.25 & 300.00 & 2000 & 500.00 & 500 \\
\hline 2 & 10752.60 & 301.29 & 2000 & 512.93 & 500 \\
\hline 3 & 10796.95 & 302.67 & 2000 & 526.69 & 500 \\
\hline 4 & 10841.30 & 304.15 & 2000 & 541.47 & 500 \\
\hline 5 & 10885.65 & 305.75 & 2000 & 557.54 & 500 \\
\hline 6 & 10930.00 & 307.53 & 2000 & 575.31 & 500 \\
\hline 7 & 10974.36 & 309.55 & 2000 & 595.47 & 500 \\
\hline 8 & 11018.71 & 311.94 & 2000 & 619.38 & 500 \\
\hline 9 & 11063.06 & 315.05 & 2000 & 650.52 & 500 \\
\hline 10 & 11107.41 & 322.57 & 2000 & 725.65 & 500 \\
\hline
\end{tabular}

\subsection{One vendor with five retailers}

Tables 11 and 12 show the parameters associated with the problem considering only one vendor with five retailers under infinite or unauthorized backorder cost conditions (i.e., P1-V1R5). The results are given in Table 13.

According to Table 13, the proposed model can be converted into the other models when the backorder costs are extremely high and the model validation is confirmed, although, as mentioned earlier, this is a bi-objective model and the second objective is the reduction of the greenhouse emissions level, value of which is calculated in the last column. However, when the backorder cost is lower and after solving the model, the distribution quantity that avoids backorder will be larger, as depicted in Table 14.

In Table 14, with one vendor and five retailers, based on the model under authorized backorder conditions, reduction of backorder cost increases distribution, order quantities and the backorder value decreases accordingly, and the vendor's profit is greater than that in the unauthorized backorder conditions. 
Table 11. The parameters for retailers in P1-V1R5 under infinite or unauthorized backorder conditions.

\begin{tabular}{cccccc}
\hline $\boldsymbol{j}$ & $\mathbf{1}$ & $\mathbf{2}$ & $\mathbf{3}$ & $\mathbf{4}$ & $\mathbf{5}$ \\
\hline$H_{b j}$ & 7 & 8 & 9 & 7 & 9 \\
$S_{b j}$ & 10 & 20 & 30 & 15 & 25 \\
$a_{j}$ & 20 & 19 & 18 & 21 & 18 \\
$k_{j}$ & 0.003 & 0.005 & 0.008 & 0.003 & 0.006 \\
$y_{j \min }$ & 2000 & 500 & 500 & 1700 & 500 \\
$y_{j \max }$ & 4000 & 3000 & 1500 & 3500 & 2500 \\
$\theta_{j}$ & 0.004 & 0.006 & 0.008 & 0.005 & 0.007 \\
$\beta_{j}$ & 0.1 & 0.1 & 0.1 & 0.1 & 0.1 \\
$\pi_{b j}$ & $\infty$ & $\infty$ & $\infty$ & $\infty$ & $\infty$ \\
$F_{j}$ & 3000 & 3000 & 3000 & 3000 & 3000 \\
\hline
\end{tabular}

Table 12. The parameters for the vendor in P1-V1R5 under infinite or unauthorized backorder conditions.

\begin{tabular}{ccccccc}
$\boldsymbol{H}_{\boldsymbol{s}}$ & $\boldsymbol{S}_{\boldsymbol{s}}$ & $\boldsymbol{C}$ & $\boldsymbol{\delta}$ & $\boldsymbol{C} \boldsymbol{C}$ & $\boldsymbol{f}$ & $\boldsymbol{N}$ \\
\hline 9 & 150 & 9850 & 7 & 100 & 0.2 & 50 \\
\hline
\end{tabular}

Also, by considering both objectives, simultaneously, $\varepsilon$-constraints are utilized to set the Pareto optimal solutions in this case (i.e., P4-V1R5). Accordingly, the gap between higher and lower limits of the objective function $\left(Z_{1}\right)$ is divided into 10 equal parts. The constraint diagram is shown in Figure 10 and the respective data are given in Table 15 .

According to Table 15, minimization of the emission function is taken into consideration first. In this case, the vendor's profit decreases (undesired) and emission level is minimized (desired), while at the end of the table, the vendor's profit increases (desired) and consequently, the green emission level increases (undesired), which is indicative of the conflict between the objective functions similar to that in the previous subsections. Figure 10 shows the $\varepsilon$-constraint diagram of P4-V1R5 sample in the case of Pareto optimal solution sets.

In a nutshell, the three samples in the developed GVMI model were solved with allowed backorder in the two-echelon supply chain through the $\varepsilon$-constraint method; values of the target objective functions were calculated by means of Pareto optimal front, while the values related to unauthorized backorder conditions were compared with those in related studies and the modeling validation was confirmed. In this regard, in

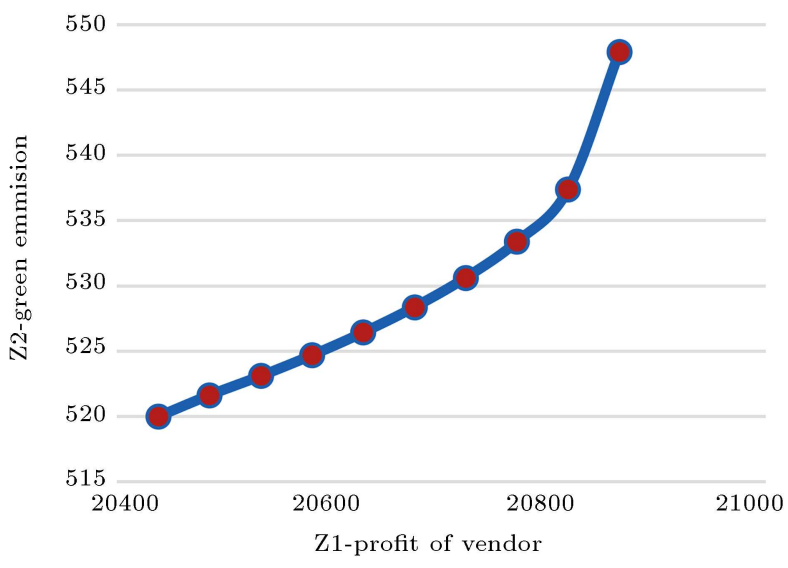

Figure 10. The Pareto optimal front of $\varepsilon$-constraint method for P4-V1R5.

the next section, the GVMI model is solved in real dimensions using three effective metaheuristics.

\section{Solving the GVMI in large-scale samples}

In this paper, three metaheuristics are employed to solve the model for large-scale samples. Upon increasing the size of the problem, the exact solver needs a longer time to perform; in real dimensions, it cannot be useful. Accordingly, the next subsection defines the instances of the test problem. The parameters of the algorithm are tuned using RSM with transformation into the single-objective approach. Then, three assessment metrics are introduced to evaluate the quality of Pareto solutions for metaheuristics. Finally, the methods are compared in terms of different criteria to confirm their efficiency in real dimensions.

\subsection{Instances}

A set of data is adopted from the literature [17] to make the comparison with metaheuristics in terms of their need and benefits of them in large-scale samples. Accordingly, by considering one vendor and several retailers, ten test problems are generated by considering different values of shortage. The values of parameters are similar to the last section as detailed before. Table 16 gives the instances of the test problem.

\subsection{Parameter settings}

As mentioned earlier, this study proposes three calibrated metaheuristics to solve the GVMI problem. Based on a set of fine-tuned parameters, the behavior of metaheuristics would be more efficient [1-5]. This

Table 13. The comparison of P1-V1R5 and that of Diabat [24].

\begin{tabular}{cccccccc}
\hline P1-V1R5 & $\boldsymbol{y}_{\mathbf{1 o p t}}$ & $\boldsymbol{y}_{\mathbf{2 o p t}}$ & $\boldsymbol{y}_{\mathbf{3} \boldsymbol{o p t}}$ & $\boldsymbol{y}_{\mathbf{4} \boldsymbol{o p t}}$ & $\boldsymbol{y}_{\mathbf{5 o p t}}$ & $\boldsymbol{Z}_{\mathbf{1}}^{*}$ & $\boldsymbol{Z}_{\mathbf{2}}$ \\
\hline This study & 2000 & 709.530 & 500 & 1700 & 535.806 & 18818.797 & 544.534 \\
Diabat [24] using a hybrid algorithm & 2126 & 653 & 567 & 1702 & 522 & 17602.15 & - \\
\hline
\end{tabular}


Table 14. The GVMI model with one vendor and five retailers considering different shortages.

\begin{tabular}{|c|c|c|c|c|c|c|}
\hline Test problem & $\pi_{b j}$ & $\boldsymbol{y}_{j \circ p t}$ & $Z_{1}^{*}$ & $Z_{2}$ & $Q_{j}^{*}$ & $b^{*}$ \\
\hline \multirow{5}{*}{ P1-V1R5 } & \multirow{5}{*}{1000000} & 2000 & \multirow{5}{*}{18818.797} & \multirow{5}{*}{544.534} & 79.058 & 79.056 \\
\hline & & 709.530 & & & 54.052 & 54.051 \\
\hline & & 500 & & & 50.000 & 50.000 \\
\hline & & 1700 & & & 79.844 & 79.843 \\
\hline & & 535.806 & & & 48.800 & 48.799 \\
\hline \multirow{5}{*}{ P2-V1R5 } & \multirow{5}{*}{1000} & 2000 & \multirow{5}{*}{18862.358} & \multirow{5}{*}{544.608} & 79.687 & 78.432 \\
\hline & & 709.879 & & & 54.523 & 53.611 \\
\hline & & 500 & & & 50.448 & 49.556 \\
\hline & & 1700 & & & 80.480 & 79.212 \\
\hline & & 536.205 & & & 49.255 & 48.384 \\
\hline \multirow{5}{*}{ P3-V1R5 } & \multirow{5}{*}{100} & 2000 & \multirow{5}{*}{19211.411} & \multirow{5}{*}{545.203} & 85.147 & 73.403 \\
\hline & & 712.667 & & & 58.595 & 50.081 \\
\hline & & 500 & & & 54.314 & 46.029 \\
\hline & & 1700 & & & 85.994 & 74.133 \\
\hline & & 539.364 & & & 53.185 & 45.072 \\
\hline \multirow{5}{*}{ P4-V1R5 } & \multirow{5}{*}{10} & 2000 & \multirow{5}{*}{20864.665} & \multirow{5}{*}{547.923} & 127.475 & 49.029 \\
\hline & & 725.645 & & & 89.819 & 33.266 \\
\hline & & 500 & & & 83.666 & 29.881 \\
\hline & & 1700 & & & 128.744 & 49.517 \\
\hline & & 553.583 & & & 83.000 & 29.643 \\
\hline
\end{tabular}

Table 15. The results of $\varepsilon$-constraint method for P4-V1R5.

\begin{tabular}{|c|c|c|c|c|c|c|c|}
\hline P4-V1R5 & $\max Z_{1}$ & $\min Z_{2}$ & $\boldsymbol{y}_{1 o p t}$ & $y_{2 o p t}$ & $y_{3 o p t}$ & $\boldsymbol{y}_{4 o p t}$ & $y_{5 o p t}$ \\
\hline 1 & 20438.883 & 520.000 & 2000 & 500.000 & 500 & 1700 & 500.000 \\
\hline 2 & 20486.192 & 521.630 & 2000 & 512.811 & 500 & 1700 & 503.492 \\
\hline 3 & 20533.501 & 523.101 & 2000 & 527.516 & 500 & 1700 & 503.492 \\
\hline 4 & 20580.810 & 524.689 & 2000 & 543.396 & 500 & 1700 & 503.492 \\
\hline 5 & 20628.119 & 526.428 & 2000 & 560.791 & 500 & 1700 & 503.492 \\
\hline 6 & 20675.429 & 528.373 & 2000 & 580.242 & 500 & 1700 & 503.492 \\
\hline 7 & 20722.738 & 530.621 & 2000 & 602.720 & 500 & 1700 & 503.492 \\
\hline 8 & 20770.047 & 533.383 & 2000 & 630.342 & 500 & 1700 & 503.492 \\
\hline 9 & 20817.356 & 537.383 & 2000 & 670.335 & 500 & 1700 & 503.492 \\
\hline 10 & 20864.665 & 547.923 & 2000 & 725.645 & 500 & 1700 & 553.583 \\
\hline
\end{tabular}

paper uses RSM offered by John and Wilson to adjust the best values of algorithm parameters [52]. In this methodology, each parameter of algorithms as a factor $\left(X_{i}\right)$ measured at two levels is coded between -1 and 1. These codes are used for the low level $\left(x_{l}\right)$ and high level $\left(x_{h}\right)$ of each variable, respectively. The independent variables of RSM are calculated through the following formula:

$$
x_{i}=\frac{2 X_{i}-x_{h}-x_{l}}{x_{h}-x_{l}}, \quad i=\{1,2, \ldots, K\}
$$

where $K$ is the number of variables. As such, $\mathrm{y}$ is utilized to formulate the variation in response variables as follows:

$$
y=\beta_{0}+\sum_{j=1}^{K} \beta_{j} x_{j}+\sum_{j=1}^{K} \sum_{i<j}^{K} \beta_{i j} x_{i} x_{j}+\sum_{j=1}^{K} \beta_{j j} x_{j j}^{2}+\varepsilon,
$$

where $y, \beta_{0}, \beta_{j}, \beta_{i j}$ represent an estimated response, a constant, the linear coefficient, and the interaction coefficient, respectively. $\beta_{j j}$ is the quadratic coefficient. Furthermore, the above equation may be considered in 
Table 16. The real dimensions of instances.

\begin{tabular}{ccc}
\hline $\begin{array}{c}\text { The number of } \\
\text { test problems }\end{array}$ & $\begin{array}{c}\text { The number of } \\
\text { retailers }\end{array}$ & $\begin{array}{c}\text { Amount of } \\
\text { shortage } \\
\left(\boldsymbol{\pi}_{\boldsymbol{b}} \boldsymbol{)}\right)\end{array}$ \\
\hline T1 & 5 & 10 \\
T2 & 10 & 10000 \\
T3 & 10 & 10000000 \\
T4 & 15 & 100 \\
T5 & 15 & 100000 \\
T6 & 25 & 1000 \\
T7 & 25 & 10 \\
T8 & 35 & 1000 \\
T9 & 45 & 10000 \\
T10 & 50 & 10000 \\
\hline
\end{tabular}

the system while there is a curvature. In this regard, Table 17 provides the parameters associated with the algorithm and their levels as well as the number of experiments.

According to RSM, the effectiveness and efficiency of the algorithms are analyzed by approximating proper parameters. By using the approach in [12], transformation of multi-objective models based on fuzzy interactive methods is utilized in this paper in the following formulas:

$$
\begin{aligned}
& \max \sum_{i=1}^{S} w_{i} \propto_{i} \\
& \text { s.t.: } \\
& Y_{i} \leq U_{i}-\propto_{i}\left(U_{i}-L_{i}\right), \\
& -1 \leq X_{i} \leq 1 \\
& 0 \leq \propto_{i} \leq 1
\end{aligned}
$$

where $S$ is the number of objective(s), $Y_{i}, w_{i}$, and $\propto_{i}$ are the $i$ th goal function ( $i$ th regression model), its weight, and its satisfactory level, respectively. As such, $U_{i}$ and $L_{i}$ are the maximum and minimum values of the $i$ th column in the payoff table. Moreover, the weights of objective functions are two times more than those at run times. Finally, Table 18 shows the tuned parameters $R$-squared $\left(R^{2}\right)$ for algorithms, as well.

\subsection{Assessment metrics for the quality of Pareto front}

This study employs three measurements to evaluate the quality of Pareto optimal solutions. These metrics were introduced in the related papers (mainly $[2,5,12]$ ). A summarized definition of these metrics is stated as follows:

- Number of Pareto Solutions (NPS): This metric shows the ability of metaheuristics to find Pareto optimal solutions. The higher value of this metric brings about better quality for algorithms [5];

- Spread of Non-dominance Solutions (SNS): It evaluates the standard distance between the ideal point and Pareto optimal solutions. For this metric, the higher value also shows the better capability of algorithms [2];

- Percentage Of Domination (POD): The objective of this metric is to measure how an algorithm can dominate other algorithm solutions. Based on the procedure of POD, all non-dominated solutions required are composed of one Pareto frontier. Next, the percentage of solutions belonging to each meta-

\begin{tabular}{|c|c|c|c|c|c|c|c|}
\hline \multirow{2}{*}{$\begin{array}{l}\text { Algorithm } \\
\text { MORDA }\end{array}$} & \multicolumn{6}{|c|}{ Factors and their levels } & \multirow{2}{*}{$\begin{array}{c}\text { No. of experiments; } \\
\text { Total number }= \\
\left(\boldsymbol{n}_{\boldsymbol{f}}, \boldsymbol{n}_{\boldsymbol{a x}}, \boldsymbol{n}_{\boldsymbol{c} \boldsymbol{p}}\right) \\
82=\left(2^{6}, 12,6\right)\end{array}$} \\
\hline & $\begin{array}{c}\text { MaxIt } \\
(150,300)\end{array}$ & $\begin{array}{c}\text { nPop } \\
(100,200)\end{array}$ & $\begin{array}{c}N_{\text {male }} \\
(15,40)\end{array}$ & $\begin{array}{c}P_{\propto} \\
(0.6,0.9)\end{array}$ & $\begin{array}{c}P_{\beta} \\
(0.4,0.7)\end{array}$ & $\begin{array}{c}P_{\gamma} \\
(0.5,0.8)\end{array}$ & \\
\hline NSGA-II & $\begin{array}{c}\text { MaxIt } \\
(150,300)\end{array}$ & $\begin{array}{c}\text { nPop } \\
(100,200)\end{array}$ & $\begin{array}{c}P_{C} \\
(0.5,0.8)\end{array}$ & $\begin{array}{c}P_{M} \\
(0.02,0.1)\end{array}$ & $\begin{array}{c}T_{C} \\
(0,3)\end{array}$ & $\begin{array}{c}T_{M} \\
(0,3)\end{array}$ & $82=\left(2^{6}, 12,6\right)$ \\
\hline MOKA & $\begin{array}{c}\text { MaxIt } \\
(200,500)\end{array}$ & $\begin{array}{c}\text { nPop } \\
(100,200)\end{array}$ & $\begin{array}{c}P N 1 \\
(0.1,0.4)\end{array}$ & $\begin{array}{c}P N 2 \\
(0.2,0.4)\end{array}$ & $\begin{array}{l}S \max \\
(1,4)\end{array}$ & & $48=\left(2^{5}, 10,6\right)$ \\
\hline
\end{tabular}
heuristic is calculated. The algorithm with higher POD appears to be a solution with better quality [12].

Table 17. Algorithms and factor levels with the total number of experiments for each method.

(MaxIt $=$ maximum number of iteration; $\mathrm{nPop}=$ maximum number of initial population; $N_{\text {male }}=$ number male RDs;

$P_{\propto}=$ percent of mating inside the harems; $P_{\beta}=$ percent of mating outside the harems; $P_{\gamma}=$ percent of male commanders;

$P_{C}=$ percent of crossover; $P_{M}=$ percent of mutation; $T C=$ type of crossover (1 to 3 ); $T_{M}=$ type of mutation (1 to 3 );

$P N 1=$ The percentage of $N 1$ Keshtels; $P N 2=$ The percentage of $N 2$ Keshtels; Smax=The maximum number of swirling process). 
Table 18. Tuned parameters of algorithms and $R$-squared $\left(R^{2}\right)$.

\begin{tabular}{|c|c|c|c|}
\hline Algorithm & Parameters & $\begin{array}{l}R^{2} \text { objective } \\
\text { function }(\%)\end{array}$ & $\begin{array}{l}R^{2} \mathrm{CPU} \\
\text { time }(\%)\end{array}$ \\
\hline MORDA & $\begin{array}{l}\text { MaxIt }=246 ; \mathrm{nPop}=148 ; N_{\text {male }}=28 \\
\quad P_{\propto}=0.85 ; P_{\beta}=0.52 ; P_{\gamma}=0.77\end{array}$ & 69 & 84 \\
\hline NSGA-II & $\begin{array}{c}\text { MaxIt }=250 ; \mathrm{nPop}=150 ; P_{M}=0.05 ; P_{C}=0.7 ; \\
T_{M}=1 ; T_{C}=3 .\end{array}$ & 64 & 66 \\
\hline MOKA & $\begin{aligned} \text { MaxIt }= & 250 ; \mathrm{nPop}=186 ; P N 1=0.25 \\
& P N 2=0.3 ; \text { Smax }=3 .\end{aligned}$ & 74 & 88 \\
\hline
\end{tabular}

Table 19. The results of algorithms in terms of assessment metrics.

\begin{tabular}{cccccccccc}
\hline & \multicolumn{3}{c}{ NPS } & \multicolumn{3}{c}{ SNS } & \multicolumn{3}{c}{ POD } \\
\cline { 2 - 9 } $\begin{array}{c}\text { Number of } \\
\text { test problem }\end{array}$ & NSGA-II & MORDA & MOKA & NSGA-II & MORDA & MOKA & NSGA-II & MORDA & MOKA \\
\hline T1 & 14 & 13 & 8 & 3540 & 4267 & 3438 & 0.16 & 0.25 & 0.18 \\
T2 & 10 & 12 & 8 & 2956 & 3867 & 2865 & 0.24 & 0.24 & 0.26 \\
T3 & 9 & 13 & 9 & 1475 & 2465 & 3968 & 0.17 & 0.28 & 0.19 \\
T4 & 8 & 10 & 9 & 3287 & 2934 & 2968 & 0.12 & 0.22 & 0.33 \\
T5 & 8 & 10 & 6 & 2465 & 2734 & 2881 & 0.09 & 0.21 & 0.32 \\
T6 & 10 & 10 & 7 & 2473 & 2910 & 2473 & 0.08 & 0.29 & 0.28 \\
T7 & 12 & 9 & 7 & 2855 & 3281 & 1945 & 0.12 & 0.34 & 0.24 \\
T8 & 9 & 9 & 9 & 2594 & 3844 & 1673 & 0.14 & 0.28 & 0.29 \\
T9 & 8 & 10 & 9 & 3193 & 3285 & 1882 & 0.16 & 0.36 & 0.22 \\
T10 & 8 & 9 & 8 & 1845 & 3882 & 2519 & 0.12 & 0.32 & 0.26 \\
\hline
\end{tabular}

\subsection{Comparison of approaches}

In this subsection, the methods are compared from different angles. First of all, the presented metaheuristics are validated with respect to a small test problem using $\varepsilon$-constraint method and the mentioned exact solver procedures (i.e., T1). Figure 11 depicts the Pareto optimal fronts for the three presented metaheuristics and an exact method. As can be seen, the algorithms exhibit an acceptable overlap with the exact method and among the metaheuristics, MORDA is more successful than others in this respect. Moreover, of note, the exact solver needs 2391 seconds to solve the model. Besides, 113, 125, and 118 seconds are considered as the time consumptions for the NSGA-II, MORDA, and MOKA, respectively. As a result, it shows that the used metaheuristics are more reliable to solve the GVMI model.

As mentioned earlier, to compare the presented metaheuristics, three assessment metrics are utilized. Table 19 shows the results of the algorithm during ten test problems for each metric. In addition, Figure 12

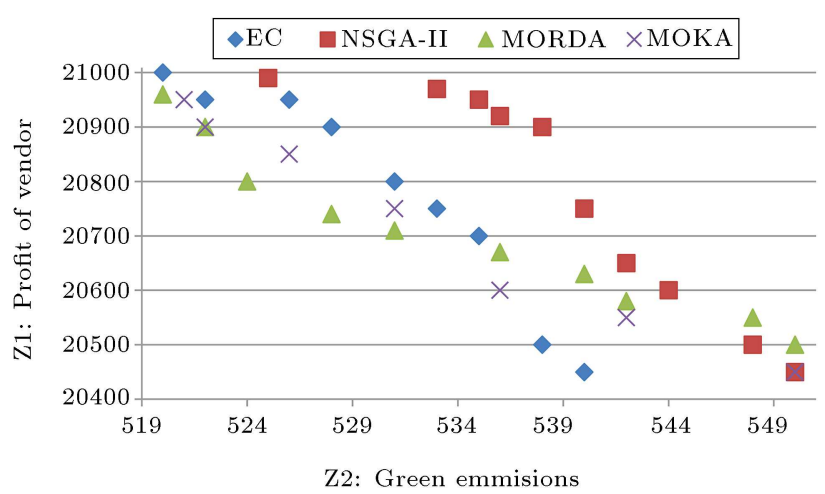

Figure 11. The non-dominated solutions for metaheuristics and exact solver for T1.

states the behavior of algorithms in terms of solution time. In this respect, results inform that NSGA-II needs a shorter time duration, and vice versa; MOKA consumes a longer time to solve the test problems.

According to the results of assessment metrics, they are validated by Relative Percentage Deviation 


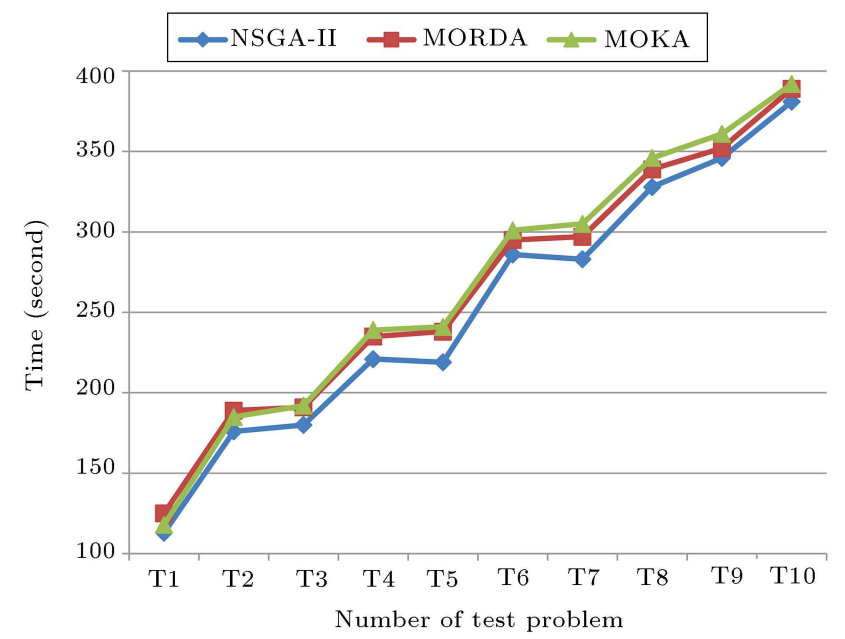

Figure 12. The behavior of algorithms in terms of solution time.

(RPD), another well-known metric, to analyze the performance of algorithms. RPD is defined using the following formula:

$$
R P D=\frac{\mid \text { Alg }_{\text {sol }}-\text { Best }_{\text {sol }} \mid}{\text { Best }_{\text {sol }}},
$$

where $A l g_{\text {sol }}$ is the output of the algorithm and Best sol $_{\text {s. }}$ is the best value ever found in problems of different sizes. Without considering the nature of assessment metrics, the lower value of RPD always points to the better capability of metaheuristics. Finally, a set of statistical analyses based on analysis of variance (ANOVA) is performed to accurately analyze the results, as seen in Table 18. In order to recognize the performance of metaheuristics, they are investigated separately. Figure 13 depicts the ANOVA analyses for the presented metaheuristics. In light of the obtained results and as indicated by the NPS metric, MORDA and NSGA-II are better than MOKA. Furthermore, in SNS, NSGA-II, and MOKA have the same behavior and MORDA exhibits a better performance. Finally, in the case of POD, MORDA, and MOKA exhibit a stronger performance than NSGA-II. In a nutshell, as can be seen, MORDA is the most successful method during all assessment metrics in terms of solution quality.

\section{Conclusion and future works}

In this paper, a bi-objective green vendor managed inventory model was proposed for a two-echelon supply chain network. The main innovation was the reduction of the greenhouse emission or the reduction of the amount of environmental pollution with respect to the transportation activities. The model was formulated by considering one vendor and several retailers. The results for small-sized problems were solved by $\varepsilon$ constraint method and compared with the related

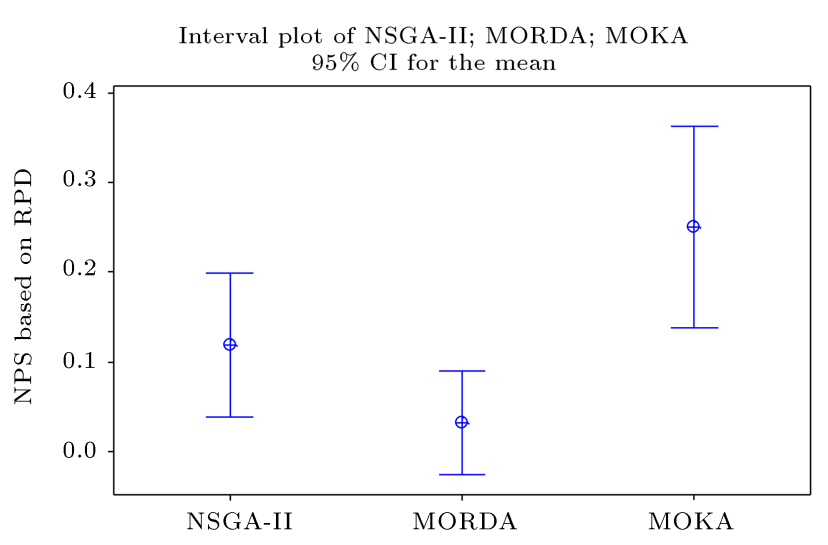

(a)

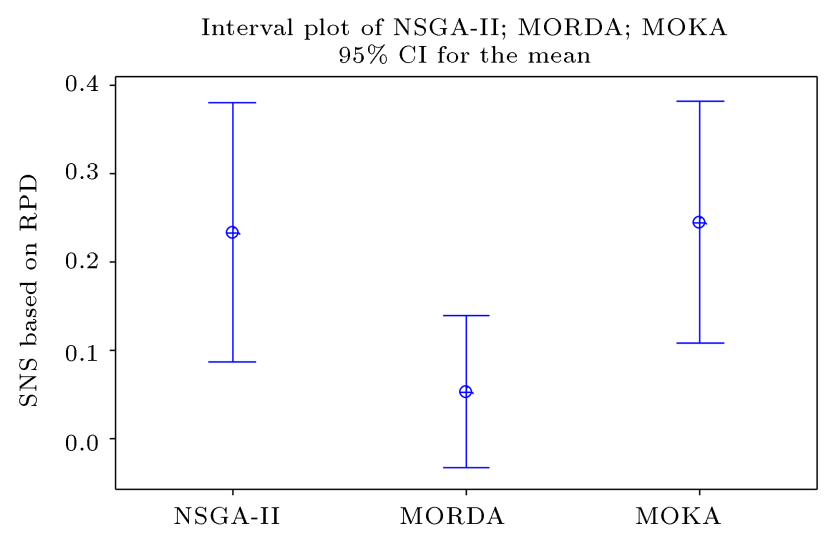

(b)

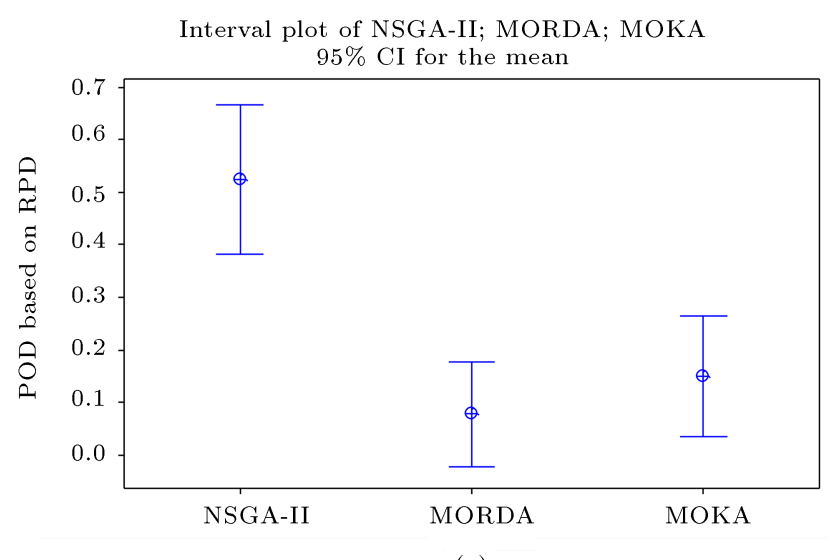

(c)

Figure 13. Results of ANOVA analyses for the three assessment metrics for used metaheuristics (i.e., for (a) NPS, (b) SNS, and (c) POD).

studies. In addition, by considering a real case study, ten test problems in a real dimension were selected. In this regard, three effective metaheuristics were offered to solve the problem. Algorithms were tuned by Response Surface Method (RSM) to obtain proper values for parameters. In addition, three assessment metrics were introduced to compare the quality of Pareto optimal solutions. Finally, Multi-Objective 
of Red Deer Algorithm (MORDA) exhibits the best performance in most of the test problems.

For future works, more comprehensive analyses of our model are suggested. The results should be compared by resolving other heuristics and metaheuristics. In addition, the presented metaheuristics can be used in other real-scale optimization problem. For future study, one can consider some real assumptions to be added to the model in practice. For instance, considering multiple periods and multiple products may be a good idea. More broadly, considering vehicle routing operation to reduce the transportation cost can be ordered by adding the same vehicles.

\section{References}

1. Tian, G., Ren, Y., Feng, Y., et al. "Modeling and planning for dual-objective selective disassembly using AND/OR graph and discrete artificial bee colony", IEEE Transactions on Industrial Informatics, 15(4), pp. 2456-2468 (2018).

2. Abdi, A., Abdi, A., Fathollahi-Fard, A.M., et al. "A set of calibrated metaheuristics to address a closedloop supply chain network design problem under uncertainty", International Journal of Systems Science: Operations \& Logistics, 8(1), pp. 23-40 (2019).

3. Tian, G., Zhang, H., Feng, Y., et al. "Operation patterns analysis of automotive components remanufacturing industry development in China", Journal of Cleaner Production, 164, pp. 1363-1375 (2017).

4. Zhang, H., Peng, Y., Hou, L., et al. "A hybrid multiobjective optimization approach for energy-absorbing structures in train collisions", Information Sciences, 481, pp. 491-506 (2019).

5. Tyan, J. and Wee, H.M. "Vendor managed inventory: a survey of the Taiwanese grocery industry", Journal of Purchasing and Supply Management, 9(1), pp. 1118 (2003).

6. Fathollahi-Fard, A.M., Hajiaghaei-Keshteli, M., and Tian, G. "An adaptive Lagrangian relaxation-based algorithm for a coordinated water supply and wastewater collection network design problem", Information Sciences, 512, pp. 1335-1359 (2020).

7. Liu, X., Tian, G., Fathollahi-Fard, A.M., et al. "Evaluation of ship's green degree using a novel hybrid approach combining group fuzzy entropy and cloud technique for the order of preference by similarity to the ideal solution theory", Clean Technologies and Environmental Policy, 22, pp. 493-512 (2020).

8. Fathollahi-Fard, A.M., Govindan, K., HajiaghaeiKeshteli, M., et al. "A green home health care supply chain: New modified simulated annealing algorithms", Journal of Cleaner Production, 139, p. 118200 (2019).

9. Tian, G., Hao, N., Zhou, M., et al. "Fuzzy grey choquet integral for evaluation of multicriteria decision making problems with interactive and qualitative indices", IEEE Transactions on Systems, Man, and Cybernetics: Systems, 51(3), pp. 1855-1868 (2019).
10. Wang, W.T., Wee, H.M., and Tsao, H.S.J. "Revisiting the note on supply chain integration in vendormanaged inventory", Decision Support Systems, 48(2), pp. 419-420 (2010).

11. Weraikat, D., Zanjani, M.K., and Lehoux, N. "Improving sustainability in a two-level pharmaceutical supply chain through vendor-managed inventory system", Operations Research for Health Care, 21, pp. 44-55 (2019).

12. Devika, K., Jafarian, A., and Nourbakhsh, V. "Designing a sustainable closed-loop supply chain network based on triple bottom line approach: A comparison of metaheuristics hybridization techniques", European Journal of Operational Research, 235(3), pp. 594-615 (2014).

13. Hajiaghaei-Keshteli, M. and Sajadifar, S.M. "Deriving the cost function for a class of three-echelon inventory system with N-retailers and one-for-one ordering policy", The International Journal of Advanced Manufacturing Technology, 50(1-4), pp. 343-351 (2010).

14. Hajiaghaei-Keshteli, M., Sajadifar, S.M., and Haji, R. "Determination of the economical policy of a threeechelon inventory system with (R,Q) ordering policy and information sharing", The International Journal of Advanced Manufacturing Technology, 55(5-8), pp. 831-841 (2011).

15. Waller, M., Johnson, M.E., and Davis, T. "Vendormanaged inventory in the retail supply chain", Journal of Business Logistics, 20(1), pp. 183-192 (1999).

16. Darwish, M.A. and Odah, O.M. "Vendor managed inventory model for single-vendor multi-retailer supply chains", European Journal of Operational Research, 204(3), pp. 473-484 (2010).

17. Kaasgari, M.A., Imani, D.M., and Mahmoodjanloo, M. "Optimizing a vendor managed inventory (VMI) supply chain for perishable products by considering discount: Two calibrated meta-heuristic algorithms", Computers \& Industrial Engineering, 103, pp. 227-241 (2017).

18. Kırılmaz, O. and Erol, S. "A proactive approach to supply chain risk management: Shifting orders among suppliers to mitigate the supply side risks", Journal of Purchasing and Supply Management, 23(1), pp. 54-65 (2017).

19. Angulo, A., Nachtmann, H., and Waller, M.A. "Supply chain information sharing in a vendor managed inventory partnership", Journal of Business Logistics, 25(1), pp. 101-120 (2004).

20. Yao, Y., Evers, P.T., and Dresner, M.E. "Supply chain integration in vendor-managed inventory", Decision Support Systems, 43(2), pp. 663-674 (2007).

21. Kwak, C., Choi, J.S., Kim, C.O., et al. "Situation reactive approach to vendor managed inventory problem", Expert Systems with Applications, 36(5), pp. 90399045 (2009). 
22. Tyan, J. and Wee, H.M. "Vendor managed inventory: a survey of the Taiwanese grocery industry", Journal of Purchasing and Supply Management, 9(1), pp. 1118 (2003).

23. Dong, Y. and Xu, K. "A supply chain model of vendor managed inventory", Transportation Research Part E: Logistics and Transportation Review, 38(2), pp. 75-95 (2002).

24. Diabat, A. "Hybrid algorithm for a vendor managed inventory system in a two-echelon supply chain", $E u$ ropean Journal of Operational Research, 238(1), pp. 114-121 (2014).

25. Nachiappan, S.P. and Jawahar, N. "A genetic algorithm for optimal operating parameters of VMI system in a two-echelon supply chain", European Journal of Operational Research, 182(3), pp. 1433-1452 (2007).

26. Sadeghi, J., Sadeghi, S., and Niaki, S.T.A. "A hybrid vendor managed inventory and redundancy allocation optimization problem in supply chain management: An NSGA-II with tuned parameters", Computers \& Operations Research, 41, pp. 53-64 (2014).

27. Nia, A.R., Far, M.H., and Niaki, S.T.A. "A hybrid genetic and imperialist competitive algorithm for green vendor managed inventory of multi-item multiconstraint EOQ model under shortage", Applied Soft Computing, 30, pp. 353-364 (2015).

28. Park, Y.B., Yoo, J.S., and Park, H.S. "A genetic algorithm for the vendor-managed inventory routing problem with lost sales", Expert Systems with Applications, 53, pp. 149-159 (2016).

29. Lee, J.Y., Cho, R.K., and Paik, S.K. "Supply chain coordination in vendor-managed inventory systems with stockout-cost sharing under limited storage capacity", European Journal of Operational Research, 248(1), pp. 95-106 (2016).

30. Khan, M., Jaber, M.Y., Zanoni, S., et al. "Vendor managed inventory with consignment stock agreement for a supply chain with defective items", Applied Mathematical Modelling, 40(15), pp. 7102-7114 (2016).

31. Pasandideh, S.H.R., Niaki, S.T.A., and Nia, A.R. "A genetic algorithm for vendor managed inventory control system of multi-product multi-constraint economic order quantity model", Expert Systems with Applications, 38(3), pp. 2708-2716 (2011).

32. Nia, A.R., Far, M.H., and Niaki, S.T.A. "A fuzzy vendor managed inventory of multi-item economic order quantity model under shortage: An ant colony optimization algorithm", International Journal of Production Economics, 155, pp. 259-271 (2014).

33. Hariga, M., Gumus, M., and Daghfous, A. "Storage constrained vendor managed inventory models with unequal shipment frequencies", Omega, 48, pp. 94-106 (2014).
34. Taleizadeh, A.A., Noori-daryan, M., and CárdenasBarrón, L.E. "Joint optimization of price, replenishment frequency, replenishment cycle and production rate in vendor managed inventory system with deteriorating items", International Journal of Production Economics, 159, pp. 285-295 (2015).

35. Beklari, A., Nikabadi, M.S., Farsijani, H., et al. "A hybrid algorithm for solving vendors managed inventory (VMI) model with the goal of maximizing inventory turnover in producer warehouse", Industrial Engineering \& Management Systems, 17(3), pp. 570587 (2018).

36. Safaeian, M., Fathollahi-Fard, A.M., Tian, G., et al. "A multi-objective supplier selection and order allocation through incremental discount in a fuzzy environment", Journal of Intelligent \& Fuzzy Systems, 37 (1), pp. 1435-1455 (2019).

37. Dai, Z., Gao, K., and Giri, B.C. "A hybrid heuristic algorithm for cyclic inventory-routing problem with perishable products in VMI supply chain", Expert Systems with Applications, 214, p. 113322 (2020).

38. Wolpert, D.H. and Macready, W.G. "No free lunch theorems for optimization", IEEE Transactions on Evolutionary Computation, 1(1), pp. 67-82 (1997).

39. Golmohamadi, S., Tavakkoli-Moghaddam, R., and Hajiaghaei-Keshteli, M. "Solving a fuzzy fixed charge solid transportation problem using batch transferring by new approaches in meta-heuristic", Electronic Notes in Discrete Mathematics, 58, pp. 143-150 (2017).

40. Fathollahi-Fard, A.M., Hajiaghaei-Keshteli, M., and Mirjalili, S. "A set of efficient heuristics for a home healthcare problem", Neural Computing and Applications, 32(10), pp. 6185-6205 (2020).

41. Bahadori-Chinibelagh, S., Fathollahi-Fard, A.M., and Hajiaghaei-Keshteli, M. "Two constructive algorithms to address a multi-depot home healthcare routing problem", IETE Journal of Research, pp. 1-7 (2019). https://doi.org/10.1080/03772063.2019.1642802

42. Fathollahi-Fard, A.M., Ranjbar-Bourani, M., Cheikhrouhou, N., et al. "Novel modifications of social engineering optimizer to solve a truck scheduling problem in a cross-docking system", Computers \& Industrial Engineering, 137, p. 106103 (2019).

43. Holland, J.H. "Adaptation in Natural and Artificial Systems: An Introductory Analysis with Applications to Biology, Control, and Artificial Intelligence", University of Michigan Press, Michigan, Ann Arbor (1975).

44. Deb, K., Agrawal, S., Pratap, A., and Meyarivan, T. "A fast elitist non-dominated sorting genetic algorithm for multi-objective optimization: NSGA-II", In International Conference on Parallel Problem Solving From Nature, pp. 849-858, Springer, Berlin, Heidelberg, (Sept., 2000). 
45. Hajiaghaei-Keshteli, M. and Aminnayeri, M. "Keshtel Algorithm (KA); a new optimization algorithm inspired by Keshtels' feeding", In Proceeding in IEEE Conference on Industrial Engineering and Management Systems, pp. 2249-2253 (2013).

46. Fathollahi-Fard, A.M. and Hajiaghaei-Keshteli, M. "Red deer algorithm (RDA); a new optimization algorithm inspired by red deer's mating" In International Conference on Industrial Engineering, IEEE., 12, pp. 331-342 (2016).

47. Fathollahi-Fard, A.M., Hajiaghaei-Keshteli, M., and Tavakkoli-Moghaddam, R. "Red deer algorithm (RDA): a new nature-inspired meta-heuristic", Soft Computing, 24(19), pp. 14637-14665 (2020). $10.1007 / \mathrm{s} 00500-020-04812-\mathrm{z}$

48. Nasiri, E., Afshari, A.J., and Hajiaghaei-Keshteli, M. "Addressing the freight consolidation and containerization by recent and hybridized meta-heuristic algorithms", International Journal of EngineeringTransactions $C$ : Aspects, 30(3), pp. 403-412 (2017).

49. Fathollahi-Fard, A.M., Niaz Azari, M., and Hajiaghaei-Keshteli, M. "An improved red deer algorithm to address a direct current brushless motor design problem", Scientia Iranica, 28(3), pp. 1750-1764 (2021).

50. Fathollahi-Fard, A.M., Ahmadi, A., and Sajadieh, M.S. "An efficient modified red deer algorithm to solve a truck scheduling problem considering time windows and deadline for trucks' departure", Evolutionary Computation in Scheduling, 6, pp. 137-167 (2020).

51. Haimes, Y.Y., Ladson, L.S., and Wismer, D.A. "Bicriterion formulation of problems of integrated system identification and system optimization", IEEE Transactions on Systems Man and Cybernetics, 3, pp. 296308 (1971).

52. Mayers, R.H., Montgomery, D.C., and AndersonCook, C.M., Response Surface Methodology: Process and Product Optimization Using Designed Experiments, John Wiley \& Sons Inc (2009).

\section{Biographies}

Mohammad Mahdi Karampour was born and raised in Kermanshah, Iran. He received BSc in Industrial Engineering at Payamnour University, Kermanshah, Iran (2015). Then, he earned his MSc in Industrial Engineering at University of Science and Technology of Mazandaran, Behshahr, Iran (2019). He currently works as a production planner and a supply chain consulter at International Companies in Iran. He is interested in business management, inventory control, supply chain and logistics along with the use of mathematical models and optimization algorithms.

Mostafa Hajiaghaei-Keshteli was born and raised in Babol, Iran. He earned his BSc from Iran University of Science \& Technology, Tehran, Iran (2004); MSc from University of Science \& Culture, Tehran, Iran (2006); and PhD from Amirkabir University of Technology (Tehran-Polytechnic), Tehran, Iran (2012), all in Industrial Engineering. He is currently an Associate Professor in Industrial Engineering at University of Science \& Technology of Mazandaran, Behshar, Iran. He has over 15 years of experience in business development, system analysis, and inventory and project management. Mostafa has also worked for many corporations in Iran and has held the positions of consulter, planning and project manager, and VP. The main focus of his research is on the area of inventory control, supply chain network, transportation, and meta-heuristics. He has published more than 100 scientific papers in high ranking journals such as ESWA, CAIE, KNOSYS, JCLP, INS, NCAA, IEEE and ASOC, etc.

Amir Mohammad Fathollahi-Fard was born and raised in Sari, Iran. Amir is currently a Research Associate at École de Technologie Supérieure, University of Québec, Montréal, Canada. He earned his $\mathrm{PhD}$ in Industrial Engineering from Amirkabir University of Technology (Tehran Poly-technique), Tehran, Iran (2021). He also received his BSc (2016) and MSc (2018) degrees in Industrial Engineering from University of Science and Technology of Mazandaran, Behshahr, Iran. His researches are about supply chain management, sustainable operations management, transportation, and logistics optimization and healthcare management. He evaluated these concepts with the use of Operations Research and Optimization algorithms mainly using Heuristics and Metaheuristics as well as Multi-Criterion Decision-Making methods. He has published more than 50 papers in the above areas in high ranking journals, e.g., JCLP, ASOC, CAIE, CTEP, EAAI, INS, etc.

Guangdong Tian (M'16) received the BS degree in Vehicle Engineering from Shandong University of Technology, Zibo, China in 2007, the MS and PhD degrees in Automobile Application Engineering from Jilin University, Changchun, China in 2009 and 2012, respectively. He is currently a Full Professor at School of Mechanical Engineering, Shandong University, China. In addition, he is a founding member of Sustainable Production and Service Automation in IEEE Robotics and Automation Society and is also a visiting scholar at Purdue University-West Lafayette. He is invited to organize several conferences and service a session chair, e.g., ICAMechS 2015 and CASE 2016. His research focuses on remanufacturing and green manufacturing, green logistics and transportation, intelligent inspection, and repair of automotive, decisionmaking, and intelligent optimization. He has published over 100 journal and conference proceedings papers in 
the above research areas including IEEE Transactions Automation Science and Engineering, IEEE Transactoins Cybernetics and IEEE-ACM Transactions on Computational Biology as well as INS, JCLP, CAIE, etc. In addition, he serves as a Frequent Reviewer for more than 50 international journals including IEEE
Transactions Automation Science Engineering, IEEE Transactions on Systems, Man, Cybernetics, Part A, and IEEE Transactions on Intelligent Transportation Systems, JCLP, CAIE, ASOC, etc. He was listed in Marquis Who's Who in the World, 30th Edition in 2013. 